'UNIVERSIDADE DE SÃO PAULO

FACULDADE DE CIÊNCIAS FARMACÊUTICAS

PROGRAMA DE PÓS-GRADUAÇÃO EM FÁRMACOS E MEDICAMENTOS

ÁREA PRODUÇÃO E CONTROLE FARMACÊUTICOS

\title{
EFETIVIDADE DA INFUSÃO ESTENDIDA DE PIPERACILINA-TAZOBACTANA - MEROPENEM NO TRATAMENTO DE PACIENTES SÉPTICOS ADULTOS QUEIMADOS ATRAVÉS DA MODELAGEM FARMACOCINÉTICA-FARMACODINÂMICA (PK/PD)
}

Vanessa Kasubeck de Souza

Dissertação para obtenção do grau de mestre

Orientadora

Profa. Dra. Silvia Regina Cavani Jorge Santos 
UNIVERSIDADE DE SÃO PAULO

FACULDADE DE CIÊNCIAS FARMACÊUTICAS

PROGRAMA DE PÓS-GRADUAÇÃO EM FÁRMACOS E MEDICAMENTOS

ÁREA PRODUÇÃO E CONTROLE FARMACÊUTICOS

\title{
EFETIVIDADE DA INFUSÃO ESTENDIDA DE \\ PIPERACILINA-TAZOBACTANA -MEROPENEM NO TRATAMENTO DE \\ PACIENTES SÉPTICOS ADULTOS QUEIMADOS ATRAVÉS DA MODELAGEM FARMACOCINÉTICA-FARMACODINÂMICA (PK/PD)
}

\author{
Vanessa Kasubeck de Souza \\ VERSÃO CORRIGIDA
}

Dissertação apresentada à

Faculdade de Ciências Farmacêuticas na

Universidade de São Paulo para obtenção do grau de

MESTRE

Profa. Dra. Silvia Regina Cavani Jorge Santos 


\section{Ficha Catalográfica}

Elaborada pela Divisão de Biblioteca e

Documentação do Conjunto das Químicas da USP.

Bibliotecária responsável pela orientação de catalogação da publicação: Marlene Aparecida Vieira - CRB - 8/5562

Souza, Vanessa Kasubeck de

S729e Efetividade da infusão estendida de Piperacilina- tazobactana Meropenem no tratamento de pacientes sépticos adultos queimados através da modelagem farmacocinética-farmacodinâmica, PK/PD / Vanessa Kasubeck de Souza. -- São Paulo, 2021.

$62 \mathrm{p}$.

Dissertação (mestrado) - Faculdade de Ciências Farmacêuticas da Universidade de São Paulo. Departamento de Farmácia - Programa de Pós-Graduação em Fármaco e Medicamentos.

Orientador: Santos, Silvia Regina Cavani Jorge

1. Grandes queimados em terapia intensiva. 2. Piperacilina/ tazobactana ou meropenem. 3. Efetividade na fase precoce do choque séptico. 4. Infusão intermitente versus estendida. 5. Abordagem PK/PD. I. T. II. Santos, Silvia Regina Cavani Jorge, orientador. 
Vanessa Kasubeck de Souza

Efetividade da infusão estendida de piperacilina/tazobactana meropenem no tratamento de pacientes sépticos adultos queimados através da modelagem farmacocinéticafarmacodinâmica (PK/PD)

\section{Comissão Julgadora}

da

Dissertação/Tese para obtenção do Título de MESTRE

Prof. Dr. Silvia Regina Cavani Jorge Santos

Orientadora / Presidente

\begin{tabular}{c}
\hline $\begin{array}{c}\text { Prof. Dr. } \\
\text { 1o. examinador }\end{array}$ \\
\hline $\begin{array}{c}\text { Prof. Dr. } \\
\text { 3o. examinador } \\
\\
\text { Po. examinador }\end{array}$
\end{tabular}

São Paulo, de de 2021 . 


\section{DEDICATÓRIA}

Com gratidão, dedico a Deus a conclusão satisfatória deste trabalho. Ele conduziu nesta caminhada, me fortaleceu nos momentos de insegurança, inspirou nos momentos difíceis e abençoou com saúde neste momento de pandemia global, e permitiu a realização deste sonho.

Aos meus pais Jesuina e Jubertino dedico esta pesquisa. Os dois sempre me motivaram a buscar evolução, incentivaram a correr atrás dos meus sonhos e foram os pilares da minha formação como ser humano, me tornando a mulher forte e independente que sou hoje. Muito obrigada!

Dedico também aos meus queridos amigos, por todo apoio, compreensão e incontáveis horas de ajuda! Gratidão! 


\section{AGRADECIMENTOS}

Agradeço primeiramente a minha querida orientadora, Professora Dr. Silvia Regina Cavani Jorge Santos, que desde o primeiro contato sempre me inspirou e motivou. Foram anos de muitos aprendizados, tanto técnicos, quanto pessoais e para vida. Seus ensinamentos nortearam todo momento a elaboração desta dissertação e sempre estimulou o desenvolvimento intelectual e até mesmo emocional. Suas correções sempre me provocaram reflexões profundas e me proporcionaram evoluções contínuas. Muito obrigada pelo aprendizado, acolhimento, dedicação e entusiasmo.

Ao programa de pós-graduação em Fármacos e Medicamentos da Faculdade de Ciências Farmacêuticas da Universidade de São Paulo, pela oportunidade, e a todos os professores excelentes que tive a oportunidade conviver.

Ao Prof. Dr. David Souza Gomez, e toda equipe médica e de enfermagem da Divisão de Cirurgia Plástica - Queimaduras do Hospital das Clínicas da Faculdade de Medicina da USP por permitirem e apoiarem integralmente a realização deste estudo.

Aos meus queridos colegas do nosso Laboratório Cecília, Claudia, Karina, Leonard, Ronaldo, Thaís, Vedilaine e Victor; Adriana e Laila da equipe técnica de farmacocinética pela parceria, contribuição e dicas oportunas durante todo o processo de construção deste trabalho.

Ao acadêmico Leonard de Vinci Kanda Kupa, pela contribuição nos momentos mais difíceis da finalização do estudo.

A equipe do hospital AC Camargo - Cancer Center pelo apoio durante o período, meus sinceros agradecimentos! 
“Há algo desmoronando, e há também algo que está nascendo. Nós escutamos o barulho do carvalho que cai, mas não escutamos o barulho da floresta que brota (...) Em geral falamos das coisas que fazem ruído, mas não falamos das sementes de consciência e de luz, que estão germinando.” 


\section{RESUMO}

DE SOUZA, V.K. - Efetividade da infusão estendida de Piperacilina-tazobactana - Meropenem no tratamento de pacientes sépticos adultos queimados através da modelagem farmacocinéticafarmacodinâmica, PK/PD. (MESTRADO) - Faculdade de Ciências Farmacêuticas, Universidade de São Paulo, 2020.

Introdução: Meropenem (MER) e Piperacilina/Tazobactana (PTZ) são agentes antimicrobianos largamente prescritos para pacientes grandes queimados internados em Unidade de Terapia Intensiva (UTI) com infecções nosocomiais causadas por Gram-negativos sensíveis CIM $2 \mathrm{mg} / \mathrm{L}$, Enterobacteriaceae, EB e Non-enterobacteriaceae, NEB. A síndrome da resposta inflamatória sistêmica (SRIS) que ocorre durante o choque séptico no grande queimado pode causar alteração na farmacocinética do paciente em terapia intensiva, de modo que a dose recomendada pode não atingir o alvo desejado contra Gram-negativos de sensibilidade intermediária CIM $>2 \mathrm{mg} / \mathrm{L}$.

Objetivo: Investigar a efetividade dos beta-lactâmicos piperacilina e meropenem na infusão estendida comparada à infusão intermitente recomendada, para os pacientes sépticos grandes queimados através da abordagem farmacocinética-farmacodinâmica (PK/PD).

Ética, casuística e procedimentos: Autor e co-autores declararam não haver conflito de interesse. O protocolo foi aprovado, registro CAAE 07525118.3.0000.0068. No presente protocolo de estudo investigaram-se 36 pacientes sépticos grandes queimados, ambos os gêneros $(12 \mathrm{~F} / 24 \mathrm{M})$ em terapia intensiva do choque séptico com piperacilina-tazobactana 4,5g q6h ou meropenem $1 \mathrm{~g}$ q8h. Os pacientes incluídos foram estratificados em dois grupos com base na administração através da infusão intermitente, 0,5 h (G1) ou da infusão estendida, 3 h (G2), ambos com 16 pacientes cada. Duas amostras sanguíneas $(1,5 \mathrm{~mL} / \mathrm{cada})$ foram coletadas no estado de equilíbrio (Steady State), $3^{\mathrm{a}}$ e $5^{\text {a }}$ hora do início da infusão. Os níveis séricos de PTZ e MER foram mensurados através de cromatografia líquida, e a farmacocinética (PK) dos dois grupos de pacientes foi comparada aos dados reportados em voluntários sadios. A abordagem PK/PD foi aplicada para avaliação da cobertura do antimicrobiano a partir da estimativa do índice de predição de efetividade (\% $f \Delta \mathrm{T}>\mathrm{CIM}$ ) e da probabilidade de alcançar o alvo terapêutico (PTA) com base no alvo PK/PD recomendado, $100 \% f \Delta \mathrm{T}>\mathrm{CIM}$.

Resultados e discussão: As características de admissão dos pacientes G1/G2 foram expressas através de mediana e interquartil: Clcr 115 (90-148) / 127 (90-170) ml/min; 30 (24-31) / 27 (24$33,5)$ anos, $70(61-75) / 71(65-75) \mathrm{kg}, 30(20-42) / 33,9(18-38,4) \%$ área total de superfície queimada, SAPS3 53 (45-57) / 48 (37,8-59,5). Na admissão dos pacientes na UTI registrou-se G1/G2: trauma térmico (17/16), trauma elétrico (1/2), lesão inalatória (11/11), ventilação mecânica (16/9) e vasopressores foram necessários em 15/8 pacientes, G1/G2. Ocorreram diferentes alterações na farmacocinética dos dois beta-lactâmicos após a infusão estendida versus a infusão intermitente quando comparadas com dados relatados em voluntários sadios. Evidenciou-se prolongamento da meia vida decorrente do aumento do volume de distribuição. Estes resultados impactaram diferentemente a cobertura. $\mathrm{O}$ monitoramento de biomarcadores inflamatórios expressos em medianas (G1/G2) evidenciou aumento do PCR: 232/183mg/L e leucocitose (leucócitos 11/14 mil cel $/ \mathrm{mm}^{3}$, neutrófilos $9 / 10 \mathrm{mil} \mathrm{cel} / \mathrm{mm}^{3}$ ) na fase precoce do choque séptico. Relativamente à microbiologia dos isolados, a erradicação dos patógenos ocorreu para todos os pacientes após a infusão estendida contra Gram-negativos sensíveis (CIM: $2 \mathrm{mg} / \mathrm{L}$ ), e de sensibilidade intermediária (CIM 4mg/L) como a $K$. pneumoniae e $P$. aeruginosa, enquanto a infusão intermitente garantiu erradicação de patógenos apenas até CIM $2 \mathrm{mg} / \mathrm{L}$.

Conclusãa: Evidenciou-se a superioridade da infusão estendida frente à infusão intermitente na cobertura dos dois antimicrobianos, no alvo terapêutico considerado $100 \% f \Delta \mathrm{T}>\mathrm{CIM}$. Registraram-se alterações na farmacocinética destes agentes nos pacientes frente aos dados reportados para voluntários sadios. Diferença significativa entre grupos (G1/G2) foi encontrada com relação meia vida biológica, e ao volume de distribuição tanto pata a piperacilina quanto para o meropenem.

Palavras-chave: Grandes queimados em terapia intensiva, piperacilina/tazobactana ou meropenem, efetividade na fase precoce do choque séptico, infusão intermitente versus estendida, abordagem $\mathrm{PK} / \mathrm{PD}$. 


\begin{abstract}
DE SOUZA, V.K. - Meropenem and piperacillin/tazobactam by extended infusion and PK/PD approach for drug effectiveness. (MESTRADO) - Faculdade de Ciências Farmacêuticas, Universidade de São Paulo, 2020.

Background: Meropenem (MER) and Piperacillin/Tazobactam (PTZ), antimicrobial betalactam agents are widely prescribed to burn patients from the Intensive Care Unit (ICU) with nosocomial infections caused by Gram-negative strains. Change in the pharmacokinetics of critically ill patient occurs during the systemic inflammatory response syndrome (SIRS) at the course of septic shock. Then, the recommended dose administered by intermittent infusion, 0.5 $\mathrm{hr}$ cannot reach the target against gram-negative strains MIC $>2 \mathrm{mg} / \mathrm{L}$.
\end{abstract}

Subject: To investigate drug effectiveness of the beta-lactams piperacilin and meropenem in extended infusion compared to the recommended intermittent infusion in critically ill septic burn patients using pharmacokinetic-pharmacodynamic (PK/PD) approach.

Ethics, Casuistry and Methods: All authors declared there is no conflict of interests. Ethical approval CAAE, register 07525118.3.0000.0068. It was investigated in the study protocol 36 septic burn patients of both genders $(12 \mathrm{M} / 24 \mathrm{~F})$, undergoing antimicrobial therapy with PTZ $4.5 \mathrm{~g} \mathrm{q} 6 \mathrm{~h}$ or MER $1 \mathrm{~g} \mathrm{q} 8 \mathrm{~h}$. Based on the chosen antimicrobial therapy and drug infusion prescribed by the physician, patients were stratified in groups with intermittent $0.5 \mathrm{~h}$ infusion (G1) or with the extended 3h infusion (G2), both groups with 16 patients each. Two blood samples were collected at the steady state $(1.5 \mathrm{~mL} /$ each $)$, at the $3^{\text {rd }}$ and $5^{\text {th }}$ hrs of starting the infusion. Serum levels were measured by liquid chromatography. Pharmacokinetics (PK) of MER or PTZ was compared to data reported in healthy volunteers for both groups of patients. $\mathrm{PK} / \mathrm{PD}$ approach was applied to estimate the drug effectiveness index $(f \Delta \mathrm{T}>\mathrm{MIC})$ and to assess the probability of target attained (PTA) based on the recommended PK/PD target, $100 \% f \Delta \mathrm{T}>$ MIC.

Results and discussion: Characteristics of patient's admission G1/G2 were: Clcr 115(90$148) / 127(90-170) \quad \mathrm{ml} / \mathrm{min} ; \quad 30(24-31) / 27(24-34) \quad y r s, \quad 70(61-75) / 71(65-75) \quad \mathrm{kg}, \quad 30(20-$ 42)/33.9(18-38.4)\% total burn surface area, SAPS3 53(45-57)/48(37.8-59.5), medians (interquartile): thermal trauma occurred (17/16), electric trauma (1/2), inhalation injury $(11 / 11)$, mechanical ventilation $(9 / 16)$ and vasopressors required in $15 / 8$ patients. It was demonstrated that different PK changes occurred for both beta-lactam agents after the extended or intermittent infusion by comparison with data reported in healthy volunteers. PK changes were related to the prolongation of biological half-life and increases on volume of distribution with impact on pharmacodynamics. On the other hand, meropenem total body clearance reduced by $50 \%$ at the earlier period of septic shock could be explained by the reduction of MER-transporter's expression in the tubular renal secretion, once only patients with renal function preserved were included in the study protocol. Inflammatory biomarkers increased at the earlier period of septic shock: C-rp 232/183mg/L; leukocytes $11 / 14 * 10^{3} \mathrm{cel} / \mathrm{mm}^{3}$, neutrophils $9 / 10^{*} 10^{3} \mathrm{cel} / \mathrm{mm}^{3}$, medians, G1/G2. Clinical and microbiological cure was obtained for all patients of G1 against $\mathrm{MIC} \leq 2 \mathrm{mg} / \mathrm{L}$ after intermittent $0.5 \mathrm{~h}$ infusion; while PK/PD target was attained for G2 patients undergoing antimicrobial therapy with MER or PTZ by extended infusion against gram negative strains $K$. pneumoniae, $P$. aeruginosa up to MIC $4 \mathrm{mg}$ L.

Conclusion: Superiority of the extended infusion over intermitent infusion was obtained for the two antimicrobials was evidenced, in the therapeutic target considered $100 \% \mathrm{f} \Delta \mathrm{T}>\mathrm{CIM}$. Changes in the pharmacokinetics of these agents were recorded in patients compared to data reported for healthy volunteers. A significant difference between groups $(\mathrm{G} 1 / \mathrm{G} 2)$ was found in relation to biological half-life and volume of distribution for both piperacillin and meropenem.

Keywords: ICU burn patients, piperacillin/tazobactam-meropenem, drug effectiveness at the earlier period of septic shock, intermitent versus extended infusion, antimicrobial therapy effectiveness, PK/PD approach. 


\section{LISTA DE FIGURAS}

Figura 1: Perfil de admissão dos pacientes queimados

Superfície corpórea total queimada avaliada na admissão dos pacientes na UTI

Figura 3: Escore de gravidade na admissão dos pacientes na UTI G1 versus G2 40

Figura 4: Dose recomendada de beta- lactâmicos e vale sérico

Figura 5: Farmacocinética da Piperacilina

Figura 6: Farmacocinética do Meropenem

Figura 7: Cobertura de beta-lactâmicos após infusão 0,5 hora versus 3 horas

Figura 8: Estudo de desfecho clínico 


\section{LISTA DE QUADROS}

Quadro 1: Dados estruturais e fisico-químicos da piperacilina 15

Quadro 2: Dados estruturais e fisico-químicos de tazobactam 16

Quadro 3: Dados estruturais e fisico-químicos do meropenem 17

Quadro 4: Classificação das queimaduras de acordo com a profundidade 19

Quadro 5: Critérios de inclusão e exclusão dos pacientes no estudo 30

Quadro 6: Prescrição de agentes beta-lactâmicos na função renal preservada 31 


\section{LISTA DE TABELAS}

Tabela 1: Características demográficas dos pacientes investigados

Tabela 2: Perfil laboratorial de biomarcadores na admissão dos pacientes

Tabela 3: Terapia empírica do choque séptico com piperacilina-tazobactana 4,5g q6h infusão intermitente $0,5 \mathrm{~h}$ versus infusão estendida 3 horas

Tabela 4: Terapia empírica do choque séptico meropenem $1 \mathrm{~g}$ q8h, infusão intermitente $0,5 \mathrm{~h} \times$ infusão lenta $3 \mathrm{hs}$ 


\begin{tabular}{|c|c|}
\hline$\% \mathrm{f} \Delta \mathrm{T}>\mathrm{CIM}$ & $\begin{array}{l}\text { Porcentagem de tempo em que a fração livre do antimicrobiano está acima } \\
\text { da concentração inibitória mínima }\end{array}$ \\
\hline$\mu \mathrm{g}$ & Micrograma \\
\hline$\propto \Lambda$ & Microlitro \\
\hline $\mathrm{ASC}^{\mathrm{ss}} \mathrm{t} / \mathrm{CIM}$ & $\begin{array}{l}\text { Agência Nacional de Vigilância Sanitária } \\
\text { Razão da área sob a curva no estado estacionário e a concentração } \\
\text { inibitória mínima }\end{array}$ \\
\hline $\begin{array}{l}\mathrm{ASC}_{\tau}^{\mathrm{ss}} \\
\mathrm{b} \text {-lactâmico }\end{array}$ & $\begin{array}{l}\text { Área sob a curva no estado de equilíbrio no intervalo de dose } \\
\text { Beta-lactâmico }\end{array}$ \\
\hline $\mathrm{CCIH}$ & Controle de Infecções Hospitalares \\
\hline cepas MR & Cepas multirresistentes \\
\hline CIM & Concentração inibitória mínima \\
\hline CLAE & Cromatografia líquida de alta eficiência \\
\hline CLcr & Clearance da creatinina \\
\hline CLT & Depuração plasmática total \\
\hline DHP-I & Desidropeptidase-I \\
\hline EB & Enterobacteriaceae \\
\hline ESBL & betalactamases de espectro estendido \\
\hline $\mathrm{F}$ & Feminino \\
\hline FDA & Food and Drug Administration \\
\hline g & Grama \\
\hline GSA & Global Sepsis Alliance \\
\hline $\mathrm{h}$ & Hora \\
\hline HIV & Vírus da imunodeficiência humana \\
\hline ILAS & Instituto Latino Americano de Sepse \\
\hline $\mathrm{IM}$ & Intramuscular \\
\hline IMC & Índice de massa corpórea \\
\hline IQ & Interquartil \\
\hline IV & Intravenoso \\
\hline kel & Taxa de eliminação \\
\hline $\mathrm{kg}$ & Kilograma \\
\hline $\mathrm{KPC}$ & Klebsiella pneumoniae carbapenemase \\
\hline $\mathrm{L}$ & Litro \\
\hline M & Masculino \\
\hline $\mathrm{mg}$ & Miligrama \\
\hline $\min$ & Minutos \\
\hline $\mathrm{mL}$ & Mililitros \\
\hline $\mathrm{mm}$ & Milímetro \\
\hline MS & Ministério da Saúde \\
\hline NAP & Não aplicável \\
\hline NEB & Non-enterobacteriaceae \\
\hline
\end{tabular}




\begin{tabular}{|c|c|}
\hline $\mathrm{O} 2$ & Oxigênio \\
\hline${ }^{\circ} \mathrm{C}$ & Grau Celsius \\
\hline P. aeruginosa & Pseudomonas aeruginosa \\
\hline PBPs & Penicillin binding protein (proteínas de ligação da penicilina) \\
\hline PCR & Proteína C-reativa \\
\hline $\mathrm{PK} / \mathrm{PD}$ & Farmacocinética-Farmacodinâmica \\
\hline PTA & Probabilidade de atingir o alvo terapêutico \\
\hline q6h & Frequência de 6 em 6 horas \\
\hline $\mathrm{q} 8 \mathrm{~h}$ & Frequência de 8 em 8 horas \\
\hline rpm & Rotações por minuto \\
\hline S. aureus & Staphylococcus aureus \\
\hline SAPS3 & Simplified Acute Physiology Score 3 \\
\hline SARS-CoV-2 & Síndrome respiratória aguda grave causada por coronavírus 2 \\
\hline Scr & Creatinina sérica \\
\hline SCTQ & Superfície corporal total queimada \\
\hline SFB & Soro fetal bovino \\
\hline SOFA & Sequential Organ Failure Assessment \\
\hline SRIS & Síndrome da Resposta Inflamatória Sistêmica \\
\hline $\mathrm{SSC}$ & Surviving Sepsis Campaign \\
\hline SUS & Sistema Único de Saúde \\
\hline$t_{(1 / 2)}$ & Meia-vida biológica de eliminação \\
\hline TBSA & Total Burn Surface Area - Superficie total corpórea queimada \\
\hline TCLE & Termo de consentimento livre e esclarecido \\
\hline tid & Time inter dose (Intervalo de dose) \\
\hline Tinf. & Tempo de infusão \\
\hline $\mathrm{TP}$ & Tempo de protrombina \\
\hline TTPa & Tempo de tromboplastina parcial ativado \\
\hline UTI & Unidade de Terapia Intensiva, UTI \\
\hline UTI-Q & Unidade de Terapia Intensiva - Queimados \\
\hline $\mathrm{Vd}$ & Volume aparente de distribuição \\
\hline Vdss & Volume aparente de distribuição no estado de equilíbrio \\
\hline WHO & World Health Organization - Organização Mundial da Saúde \\
\hline WHO / OMS & Organização Mundial da Saúde \\
\hline$\beta$-lactamase & Betalactamase \\
\hline$\tau$ & "tau" (Intervalo de dose na terapia de doses múltiplas) \\
\hline
\end{tabular}




\section{SUMÁRIO}

1. INTRODUÇÃO 15

1.1 Estrutura química e propriedades da piperacilina e tazobactam 15

1.2 Estrutura química e propriedades do meropenem 16

$\begin{array}{lll}1.3 & \text { Queimaduras } & 17\end{array}$

1.4 Choque séptico 21

1.5 Farmacocinética nos pacientes queimados e em choque séptico 22

1.6 Abordagem PK/PD 22

1.7 Efetividade da piperacilina-tazobactana 24

1.8 Efetividade do meropenem 26

2. OBJETIVO DO ESTUDO 28

3. MATERIAL E MÉTODOS 29

3.1 Aspectos éticos 29

3.2 Tipos de comparação e desfechos 29

$\begin{array}{lll}\text { 3.3 Etapas do estudo } & 30\end{array}$

4. RESULTADOS 38

$\begin{array}{lll}4.1 & \text { Casuística } & 38\end{array}$

5. DISCUSSÃO 48

6. CONCLUSÃO 54

7. REFERÊNCIAS 55

8. APÊNDICE 60

8.1 Termo de consentimento livre esclarecido (TCLE) 60 


\section{INTRODUÇÃO}

\subsection{Estrutura química e propriedades da piperacilina e tazobactam}

A piperacilina é um antimicrobiano betalactâmico ( $\beta$-lactâmico) de amplo espectro que apresenta atividade contra patógenos gram-negativos e gram-positivos lançado na década de 70 para administração sistêmica nos pacientes internados em unidade hospitalar, dentre eles aqueles em Unidade de Terapia Intensiva, UTI (VERBIST, 1977).

Quadro 1: Dados estruturais e físico-químicos da piperacilina (PUBCHEM).

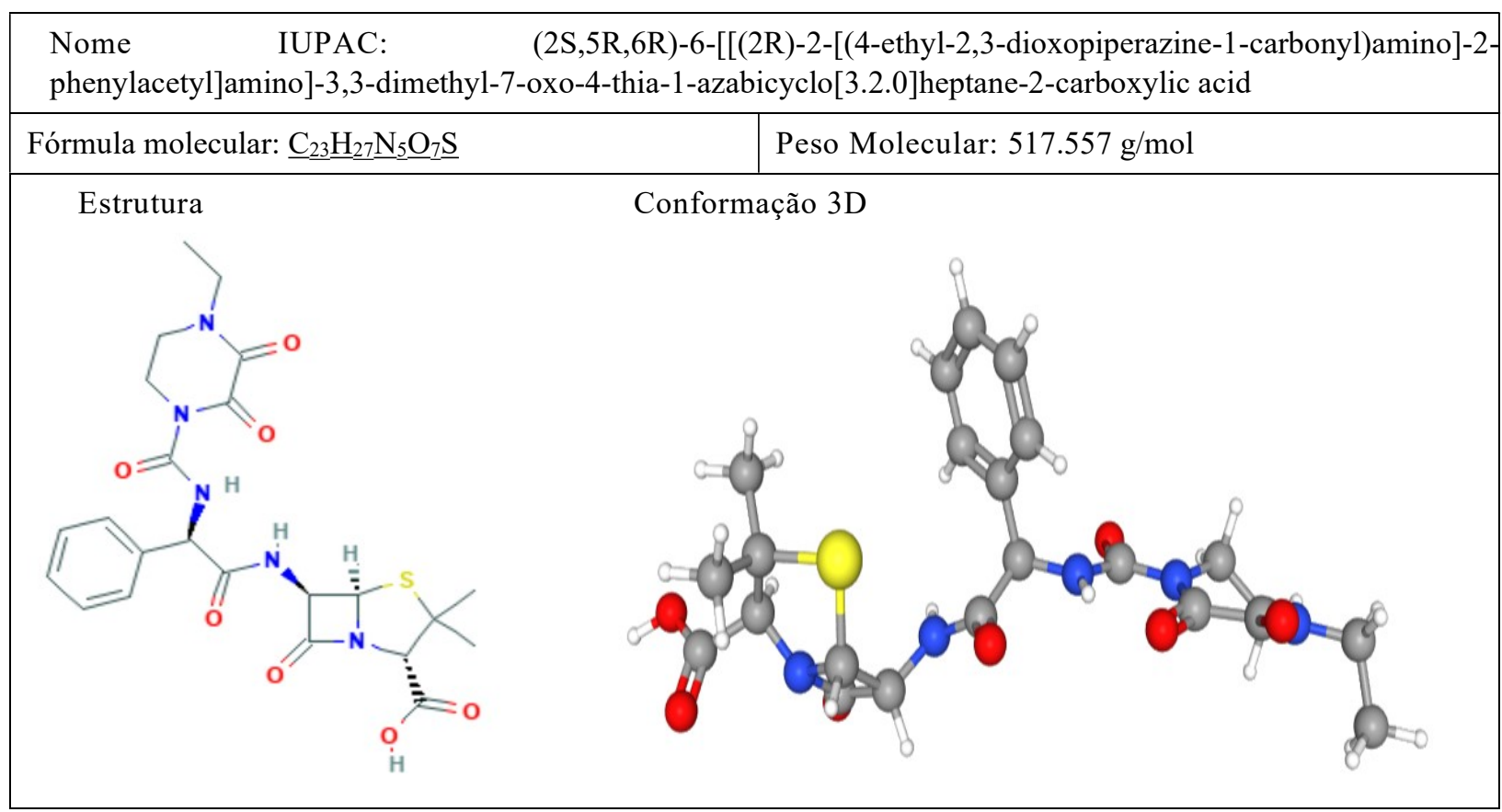

Fonte: PUBCHEM

Com o início do uso da piperacilina, esse agente terapêutico foi retirado do uso hospitalar após registro de emergência bacteriana pelas cepas produtoras de $\beta$ lactamases (FU, NEU, 1980; CHOW et al., 1991).

Subsequentemente, a mesma molécula foi disponibilizada novamente para uso hospitalar associada à tazobactana (também chamado tazobactam), um potente inibidor das $\beta$-lactamases produzidas pelos patógenos hospitalares responsáveis pelo desenvolvimento de resistência ao antimicrobiano, pois, pode ocorrer a seleção de cepas mutantes em consequência de alterações na farmacocinética desse $\beta$-lactâmico nos pacientes críticos com risco de subterapia, e consequentemente impacto no desfecho clínico. Desta forma, a associação com tazobactana introduziu resultados satisfatórios no 
curso clínico da terapia do choque séptico causado por enterobactérias sendo, e naquela época tornou-se o agente terapêutico de primeira escolha na suspeita de sepse por patógeno hospitalar no paciente crítico de UTI (JONES; BARRY, 1989; WISE et al., 1991).

É importante ressaltar que este cenário foi possível até o aparecimento e disseminação de isolados produtores de beta-lactamases de espectro estendido (ESBL) e beta-lactamases AmpC ou carbapenemases (enzimas capazes de hidrolisar penicilinas, cefalosporinas da $1^{\mathrm{a}}$ à $3^{\mathrm{a}}$ geração, cefamicinas e inibidores de beta-lactamases) (UDY et al., 2013).

Quadro 2: Dados estruturais e fisico-químicos de tazobactam (PUBCHEM).

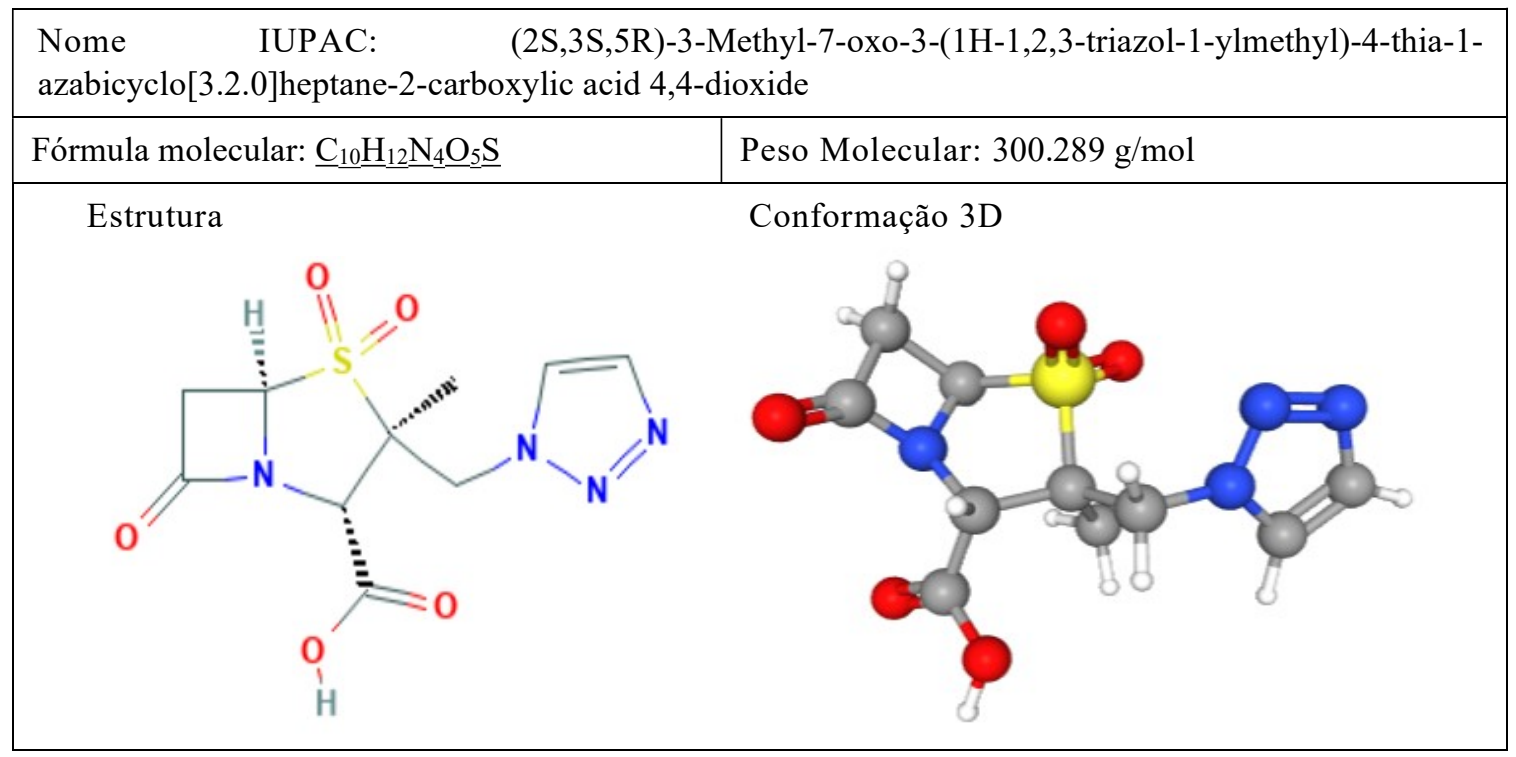

Fonte: PUBCHEM

\subsection{Estrutura química e propriedades do meropenem}

O meropenem é um agente antimicrobiano carbapenêmico de amplo espectro, que foi aprovado para uso pelo FDA (Food and Drugs Administration) na década de 90. A molécula foi sintetizada na década de 80 e registrada com o código SM-7338 e lançada comercialmente com o nome Merrem pelo laboratório Zeneca Pharmaceuticals (SUNAGAWA, et al., 1990; BLUMER, 1997; MEROPENEM, 1995).

Os carbapenêmicos são antibióticos que contêm em sua estrutura um anel $\beta$-lactâmico (também é comum às penicilinas e cefalosporinas), sendo este anel um alvo para a enzima $\beta$ - 
lactamase que algumas cepas de bactérias resistentes produzem, contudo, meropenem é relativamente estável na presença de beta-lactamases. Estes carbapenêmicos impedem a formação da parede celular bacteriana intacta e funcional, através da inibição da enzima transpeptídica bacteriana responsável pela síntese da parede celular, que resulta lise celular (MEROPENEM, 1995).

Quadro 3: Dados estruturais e fisico-químicos do meropenem (PUBCHEM).

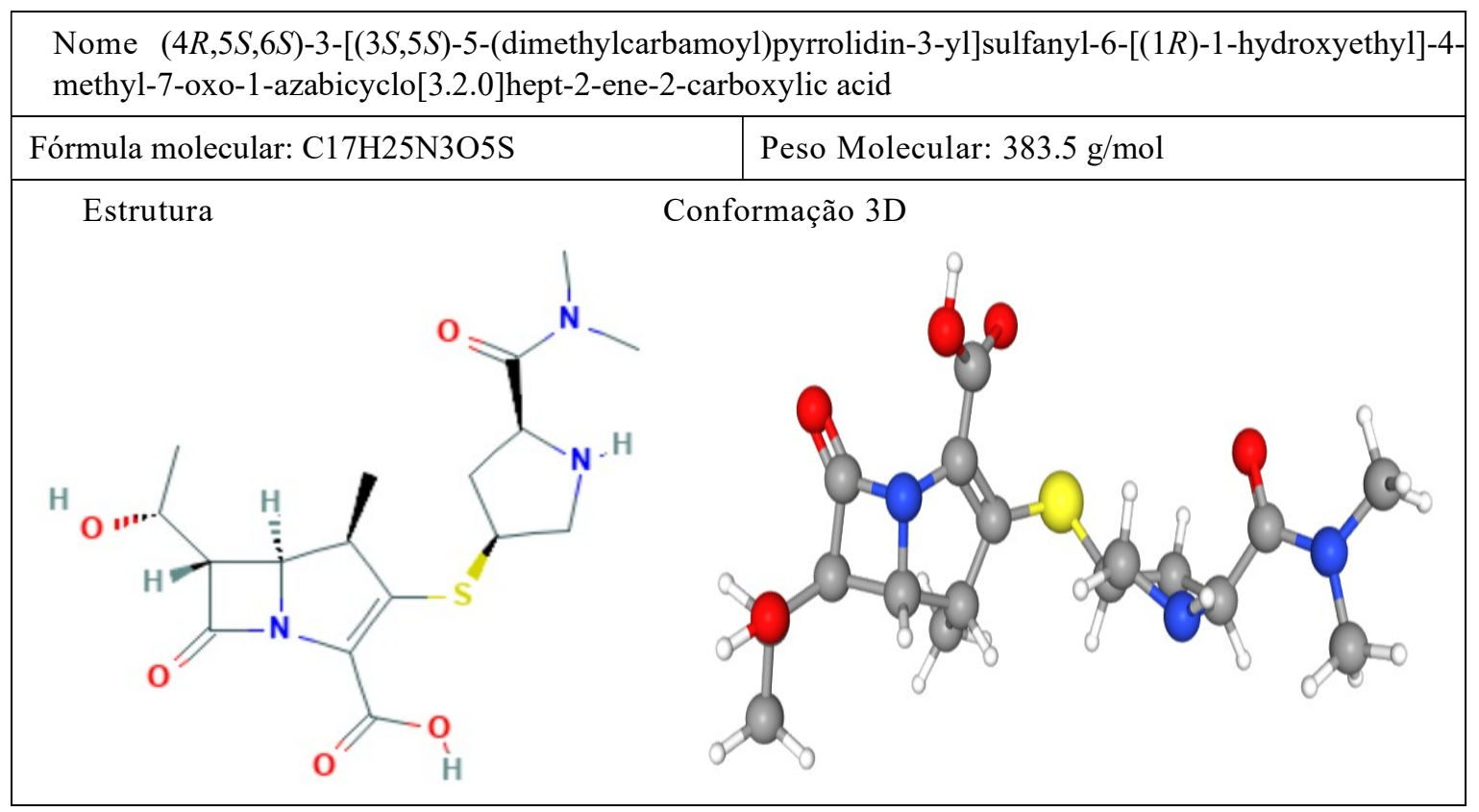

\subsection{Queimaduras - Epidemiologia e complicações}

Segundo o Ministério da Saúde (MS), queimadura é toda lesão provocada pelo contato direto com alguma fonte de calor ou frio, produto químico, corrente elétrica, radiação, ou mesmo relacionado a alguns animais e plantas, como larvas, água-viva, urtiga, dentre outros (MINISTÉRIO DA SAÚDE, 2015).

Nos Estados Unidos da América (EUA) em 2006 as queimaduras moderadas a graves correspondiam por aproximadamente 100.000 de casos ao ano, e cerca de 5.000 pacientes morriam devido suas complicações (CHURCH et al., 2006).

Em 2008, estimava-se que anualmente 300.000 mil pessoas morriam de queimaduras relacionadas ao fogo, sendo a ocorrência de 95\% nos países de baixa e média renda, e mais comum em pessoas de nível socioeconômico baixo; porém dados epidemiológicos indicam que o gênero e a faixa etária variam de acordo com a região. Neste mesmo ano, mais de 
410.000 queimaduras ocorreram nos Estados Unidos da América, com aproximadamente 40.000 pessoas requerendo hospitalização (WHO, 2018).

Corroborando as estatísticas, a Sociedade Brasileira de Queimaduras (SBQ) estima que no Brasil ocorra cerca 1 milhão de acidentes por queimaduras ao ano, e destas, 100 mil necessitam de atendimento hospitalar com óbito podendo chegar à 2,5\%. Em nível mundial, de acordo com a OMS, as queimaduras estão associadas a altas taxas de morbimortalidade, pois comprometem a pele, que é maior órgão do corpo humano e é fundamental para a preservação da homeostasia, termorregulação e proteção contra a infecções, pois a ruptura da solução de continuidade tissular, ocasiona um desequilíbrio entre a microbiota normal, tornando vulnerável a invasões patógenos que ocasionam a infecção (FRANCK et al., 2017; HENRIQUE et al., 2013).

Consideradas um problema de saúde pública global, as queimaduras são responsáveis por aproximadamente 180 mil mortes anualmente. Quanto aos casos não fatais, estas são a principal causa de morbidade, incluindo desfiguração e incapacidade, frequentemente com estigma e rejeição resultante, hospitalização prolongada e aumento de gastos com a saúde. $\mathrm{Na}$ África do Sul, por exemplo, estima-se que US \$ 26 milhões são gastos anualmente para cuidar de queimaduras, sem contar os custos indiretos, necessidade de cuidado prolongado, traumas emocionais e comprometimento de recursos familiares, também contribuem para o impacto socioeconômico (WHO, 2018).

No Brasil, estudos indicam que a maior incidência ocorre em homens adultos LACERDA et al (2010). Estes autores, num estudo epidemiológico de 101 pacientes internados na ala de queimados do Hospital São Paulo sob tratamento no período de 1 ano, concluiram que cerca de $70 \%$ dos pacientes eram do gênero masculino, e média de 34 anos.

SOUZA et al (2009) em estudo retrospectivo analisou 472 pacientes internados na unidade de queimaduras do Hospital do Servidor Público Estadual de São Paulo entre maio de 2005 e julho de 2008; neste estudo constatou-se que a maior parte dos pacientes eram homens adultos (47\% das internações). Com relação ao gênero, 68\% eram homens com idade superior à 14 anos.

Estudo conduzido em 90 serviços habilitados para o atendimento de urgência e emergência no âmbito do Sistema Único de Saúde (SUS), em 23 capitais brasileiras e no Distrito Federal, no período de setembro a dezembro de 2017, analisou 789 vítimas de 
acidentes com queimaduras constatou maior frequência em adultos com idade entre 20 e 39 anos (40,7\%) e gênero masculino 57\% (MALTA et al., 2020).

Em 2020, devido a instalação de uma pandemia mundial de COVID-19 causada pelo coronavírus 2 que resulta em síndrome respiratória aguda grave (SARS-CoV-2), houve um aumento na utilização do alcool (gel e líquido) como agente higienizador de prevenção de contaminação com o vírus, portanto, a SBQ têm alertado a população devido à tendência de aumento dos acidentes ocasionando queimaduras. Dados de monitoramento de 36 Centros de Tratamento de Queimados (CTQs) e hospitais gerais pelo país, de março a agosto de 2020, contabilizou no período, 497 internações por queimaduras com álcool líquido e/ou gel (SOCIEDADE BRASILEIRA DE QUEIMADURAS, 2020).

A Sociedade Brasileira de Cirurgia Plástica (SBCP) define a classificação das queimaduras de acordo com sua profundidade e sinais, conforme o quadro 4 a seguir:

Quadro 4: Classificação das queimaduras de acordo com a profundidade

\begin{tabular}{|l|l|l|}
\hline Queimaduras & Grau de Profundidade das Lesões & Sinais \\
\hline Primeiro Grau & Lesões apenas da Epiderme & Eritema \\
\hline Segundo Grau & Lesões da Epiderme e parte da Derme & Eritema + Bolha \\
\hline Terceiro Grau & Lesões da Epiderme e da Derme & Branca Nacarada \\
\hline
\end{tabular}

Fonte: Adaptado de PICCOLO et al., 2008.

Em literatura relata-se ainda o termo lesão de quarto grau para queimaduras que atingem estruturas mais profundas como fáscias, músculos e ossos. Importante ainda relatar a lesão inalatória que pode ser causada por inalação de fumaça tóxica ou fuligem podendo levar a importantes fisiológicas prejudiciais à respiração e facilita a ocorrência de infecção, colapso alveolar e atelectasia, obstrução das vias aéreas e necessidade de ventilação mecânica (VM), que podem propiciar aumento significativo da morbi-letalidade (BITTNER et al., 2015).

Pacientes grandes queimados com mais de $40 \%$ da superfície corporal total queimada (SCTQ) possuem maior incidência de letalidade, pois, são submetidos a um alto número de procedimentos invasivos e estão sob um complexo quadro inflamatório resultante da fisiopatologia da injúria térmica. Estima-se ainda que $75 \%$ de todas as mortes estão atualmente relacionadas à sepse ou outras complicações relacionadas a infecção e/ou lesão inalatória (CHURCH et al., 2006). 
No paciente queimado, o processo infeccioso é ocasionado pela quebra da barreira de proteção, pela presença de proteínas degradadas e pelo tecido desvitalizado devido à lesão da área queimada. Este processo inflamatório favorece a obstrução vascular, que consequentemente dificulta a entrada de antibióticos e de componentes celulares do sistema imune na área queimada. Fatores como imunossupressão, translocação bacteriana, internação prolongada e uso irracional e inadequado de agentes antibióticos no paciente queimado favorecem para o desenvolvimento da sepse e o surgimento de cepas multirresistentes a diversos antimicrobianos (HENRIQUE et al., 2013)

As alterações fisiológicas causadas por queimaduras extensas relacionadas à SCTQ maiores que 25\%, associada à SIRS (síndrome da resposta inflamatória sistêmica), resulta em instabilidade hemodinâmica, que propiciam o desenvolvimento de alterações na farmacocinética e na farmacodinâmica dos agentes antimicrobianos. Tais alterações podem ser agravadas pela presença do choque séptico, associado ao estado crítico do paciente na UTI e uso de determinados medicamentos (como vasoativos e/ou diuréticos) além na presença de interações medicamentosas. A extensão bem como a profundidade da área queimada também aumenta a incidência de infecção causada por patógeno hospitalar no paciente crítico (NORBURY et al., 2016).

O rompimento da integridade da barreira juntamente com a presença de feridas, o tempo de internação prolongado, a presença de imunossupressão, utilização de cateteres, sondas e realização de procedimentos invasivos favorecem a colonização bacteriana e fúngica no paciente grande queimado, tornando-o mais propenso a infecções causadas por patógenos hospitalares quando comparada à lesão cirúrgica no pós-operatório. A infecção é uma das maiores complicações deste perfil de pacientes e estima-se que $75 \%$ da mortalidade estejam relacionadas à presença de infecção (BHARWANA et al., 2016).

Os patógenos Gram-negativos, incluindo-se as enterobactérias, são os maiores causadores da alta gravidade e morbi-mortalidade nos pacientes queimados, devendo-se destacar, ainda a Pseudomonas aeruginosa e a Klebsiella Pneumoniae (KPC), patógenos gram-negativos responsáveis por óbitos decorrentes dos casos de emergência bacteriana (VAN DUIN et al., 2016). Gaieske e colaboradores (2010) investigando fatores que podem reduzir a mortalidade em pacientes críticos em choque séptico verificaram que a escolha adequada do antimicrobiano e o início precoce da terapia foram relacionados à redução significativa na taxa de mortalidade; adicionalmente a remoção de tecidos necróticos, 
suprimento adequado de sangue e oxigênio às áreas lesionadas, e o bom suporte nutricional também devem ser considerados (GAIESKE et al., 2010, RHODES et al., 2017).

\subsection{Choque séptico}

O choque séptico causa uma disfunção orgânica potencialmente fatal que ocorre pela resposta do hospedeiro desregulada à infecção (RUDD et al., 2020; RHODES et al., 2017). O desfecho clínico na maioria dos casos de alto risco é o óbito dos pacientes portadores de infecções nosocomiais associadas a diversas comorbidades, incluindo as infecções por vírus como mais recentemente pelo SARS-CoV-2 (GSA, 2020). Dentre 47 a 50 milhões de casos diagnosticados anualmente no mundo, pelo menos 11 milhões de pacientes evoluem a óbito; sendo majoritariamente concentrados nos países subdesenvolvidos (RUDD et al., 2020).

No Brasil, um estudo de prevalência realizado em 2015 conduzido em 230 UTIs apontou que $30 \%$ dos leitos estão ocupados por pacientes em choque séptico; estima-se ainda com base nestes dados, que o índice de óbito seja de 50\%. Esses achados indicam que a gravidade da infecção resulte num elevado custo social e econômico para o país (ILAS, 2015).

Além disso, conforme o último relatório anual do Instituto Latino Americano da Sepse (ILAS), o aumento do número de pacientes em choque séptico foi exponencial entre 2005 e 2019 no Brasil com registro de 171 casos no ano de 2005, 1.936 casos (2010), 10.570 casos (2015), e 15.571 casos em 2019, com destaque para a população idosa com pneumonia como sítio primário de infecção. As taxas de letalidade recentes, como medida de prognóstico, expressam que do total de pacientes portadores de diversos tipos de infecção evoluindo para o choque séptico, elevada proporção de óbitos destes pacientes tem ocorrido no Brasil (ILAS, 2019).

Em vista do crescente desafio ao uso de antimicrobianos para o tratamento adequado e controle efetivo dos quadros infecciosos, a ANVISA e a OMS têm reforçado que o combate à resistência bacteriana e a prevenção do desenvolvimento de cepas multirresistentes (MR) é urgente; uma vez que os profissionais responsáveis pelo controle das infecções hospitalares têm reportado aumento expressivo da concentração inibitória mínima (CIM) de agentes antimicrobianos contra os patógenos nosocomiais (ANVISA, 2017; OMS, 2015). 
No último consenso internacional realizado na Bélgica (2016), o Surviving Sepsis Campaign (SSC) publicou que a prescrição do antimicrobiano na fase precoce do choque séptico é fundamental para garantia de manutenção da vida de pacientes críticos com infecções graves na UTI. Dessa forma, essa população exige da equipe clínica alteração de conduta imediata e o monitoramento contínuo destes pacientes em terapia intensiva através da contínua vigilância hemodinâmica, respiratória, renal e infecciosa (RHODES et al., 2017).

\subsection{Farmacocinética nos pacientes queimados e em choque séptico}

Os pacientes queimados podem apresentar alterações farmacocinéticas na fase aguda da inflamação (primeiras 18 horas) devido alguns fatores fisiopatológicos como perda de fluido proteico do sistema vascular através de alterações na permeabilidade vascular, com hipovolemia, redução do débito cardíaco e hipoperfusão tecidual causando redução do fluxo renal e da taxa de filtração glomerular. Já na fase seguinte (hipermetabólica) ocorre reposição adequada de fluidos, aumento no débito cardíaco, com concomitante aumento no fluxo sanguíneo de rins e fígado, aumento da filtração glomerular, redução da função tubular, aumento significativo do fluxo sanguíneo no fígado e alterações significativas nos níveis de proteínas plasmáticas. Todas estas alterações influenciam as respostas aos antimicrobianos devido alteração nos parâmetros farmacocinéticos (WEINBRER, 1999).

Além das alterações provenientes da queimadura, alterações derivadas da sepse e do complexo processo inflamatório sistêmico envolvido pode gerar modificação da farmacocinética dos antimicrobianos utilizados devido aumento do debito cardíaco, alteração das proteínas plasmáticas, disfunções orgânicas renal e/ou hepática, que resultam alterações da depuração plasmática dos fármacos e no volume de distribuição, ocasionando alterações nas concentrações plasmáticas, que consequentemente impacta na efetividade terapêutica (ROBERTS \& LIPMAN, 2009).

\subsection{Abordagem PK/PD}

A abordagem farmacocinética/farmacodinâmica (PK/PD) nos permite relacionar quantitativamente a relação dose-exposição-resposta dos medicamentos pela associação dos parâmetros farmacocinéticos, com a resposta obtida, mensurada através da farmacodinâmica. Deste modo, o resultado da abordagem PK/PD traduz os efeitos em relação ao tempo, 
decorrente de determinado regime terapêutico numa população, podendo ser preditivos e/ou descritivos dos efeitos da farmacodinâmica no decurso do tempo. Os modelos preditivos, quando realizados adequadamente e em tempo real, podem ser usados para auxiliar os regimes de doses iniciais bem como ajustes de dose necessários, podendo adicionar evidência na certeza de uma decisão clínica resultando em melhores desfechos relacionados aos benefícios clínicos (ONUFRAK et al., 2016).

A abordagem PK/PD na utilização de agentes antimicrobianos nos permite verificar a predição da efetividade relacionada à cobertura contra os patógenos sensíveis considerando o perfil farmacocinético de um determinado paciente correlacionando-o ao farmacodinâmico. A modelagem PK/PD varia de acordo com a classe do antimicrobiano e permite correlacionar o perfil farmacocinético do antimicrobiano (medida in vivo) com a sensibilidade do microrganismo a esse antimicrobiano, representada pela concentração inibitória mínima CIM (medida in vitro), para obtenção do índice de predição da efetividade antimicrobiana ao patógeno. A forma de cálculo para a realização desta abordagem, depende do tipo (classe) do antimicrobiano ou antifúngico utilizado, e para seus cálculos, devemos considerar as características de ação, podendo ser a efetividade dependente do tempo (1), dependente da concentração máxima (2) ou ainda dependente da concentração e do tempo (3) conforme descrito inicialmente por RYBAK et al., 2006.

(1) Dependente do tempo em que o nível sérico permanece acima da concentração inibitória mínima do patógeno (\% $\%$ CIM);

(2) Dependente da razão do pico sérico no platô e a CIM do patógeno ( $\left.\mathrm{C}^{\mathrm{ss}} \mathrm{max} / \mathrm{CIM}\right)$;

(3) Dependente dos níveis séricos no decurso do tempo, expresso através da razão da área sob a curva e a concentração inibitória mínima e a CIM do patógeno $\mathrm{ASC}^{\mathrm{ss}} \tau / \mathrm{CIM}$.

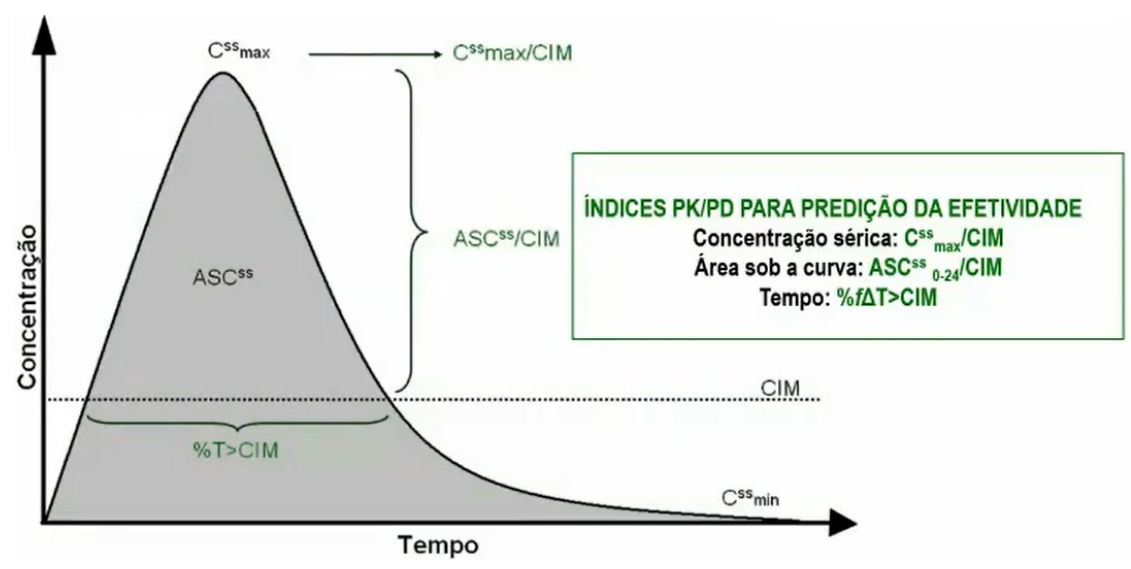




\subsection{Efetividade da Piperacilina-Tazobactana}

A molécula da piperacilina foi desenvolvida como novo beta-lactâmico na década de setenta sob número investigacional de T-1220 nos centros de desenvolvimento da Lederle Laboratories na cidade de Wayne, New Jersey, USA. A molécula mostrou-se promissora como antimicrobiano beta-lactâmico, sendo aprovada pela Agência Regulatória nos Estados Unidos da América do Norte, e registrada pela Lederle Laboratories em 1977 sob denominação de PIPRACIL® IV/IM, piperacilina sódica, uso hospitalar, forma injetável pelas vias sistêmica e intramuscular. A indicação constante em bula era para o tratamento de infecções causadas por patógenos hospitalares nos pacientes hospitalizados, contra bactérias Gram-negativas com destaque para as enterobactérias e a $P$. aeruginosa e dentre as Gram positivas contra o $S$. aureus sensíveis a oxacilina (SWEET et al., 1983).

Posteriormente, registrou-se a fusão dessa empresa com a denominação de WyethLederle. Na década de 90, em consequência de sucessivas fusões o grupo teve a denominação de Wyeth Whitehall. Por se tratar de beta-lactâmico de amplo espectro, agente de primeira linha recomendado para terapia empírica das infecções graves nos pacientes nas UTIs, e como se registrou desenvolvimento de resistência contra as cepas sensíveis, o grupo Wyeth Whitehall investiu no desenvolvimento de combinação da piperacilina sódica com inibidores da beta-lactamase. Testaram-se então as diversas combinações da piperacilina com tazobactana, subactana e ácido clavulônico através de estudos controlados prospectivos, registrando a superioridade de efetividade pela combinação da piperacilina-tazobactam (KUCK et al., 1989).

A dose diária de bula recomendada inicialmente pelo fabricante Lederle Laboratories pela aprovação do produto PIPRACIL® em 1977 teve indicação para administração sistêmica, infusão de $0,5 \mathrm{~h}$, nos pacientes adultos hospitalizados na dose de pendente da função renal, entre 2 a 4 g, de 3 a 4 x dia de piperacilina sódica IV ou IV. Posteriormente, outros regimes foram testados para garantir a efetividade do novo beta-lactâmico (KIM et al., 2002; BLANCHET et al., 2008).

A efetividade da piperacilina, agente beta-lactâmico de uso hospitalar depende do tempo em que o patógeno é exposto ao antimicrobiano; portanto é um agente de efetividade tempo-dependente. A cobertura desse agente determinada pela abordagem PK/PD é expressa através da porcentagem do intervalo entre doses em que a concentração sérica da piperacilina 
livre permanece acima da CIM do patógeno ( $\% f \Delta \mathrm{T}>\mathrm{CIM})$. O valor numérico para o índice de efetividade recomendado anteriormente pelo posterior lançamento do produto piperacilina combinada a tazobactana TAZOCIN ${ }^{\circ}$ era de $50 \%$ e $70 \% f \Delta \mathrm{T}>\mathrm{CIM}$ contra Gram-positivos e Gram-negativos, respectivamente (KAYS et al., 1999).

Deve-se destacar que se registrou o desenvolvimento de resistência ao antimicrobiano pela seleção de mutantes para a Klebsiella pneumoniae pela utilização do TAZOCIN® para o tratamento das infecções causadas por patógenos hospitalares, bem como pela ausência de monitoramento sérico durante a terapia do choque séptico (BAQUERO et al., 2008; CARLIER et al., 2015; ABDUL-AZIZ et al., 2016).

Desta forma, tornou-se imperativo investigação relativa ao valor numérico estabelecido inicialmente para o índice de efetividade da piperacilina de $70 \% f \Delta \mathrm{T}>\mathrm{CIM}$ contra Gram-negativos (enterobactérias e $P$ aeruginosa) aumentado para $100 \% f \Delta \mathrm{T}>\mathrm{CIM}$, novo valor recomendado por Abdul-Aziz et al (2016), Silva Junior et al (2017) para estudo de pacientes críticos em terapia intensiva. Então, o novo índice de predição da efetividade da piperacilina foi fixado em $100 \% f \Delta \mathrm{T}>\mathrm{CIM}$ na erradicação de patógenos hospitalares sensíveis causadores das infecções graves pelas Enterobacteriaceae e Pseudomonas aeruginosa, CIM $>2 \mathrm{mg} / \mathrm{L}$ de forma a se evitar a seleção mutantes (KAYS et al., 1999; ABDUL-AZIZ et al., 2016; SILVA JUNIOR et al., 2017).

Como a resistência bacteriana à piperacilina ocorreu a partir da infusão intermitente mesmo após sua combinação à tazobactana (recomendação em bula após o novo lançamento), tornou-se evidente a utilização de estratégias relacionadas ao período de infusão para se tentar aumentar a efetividade deste antimicrobiano nos pacientes sépticos com função renal aumentada pelo uso de vasopressores. Recentemente, reportou-se a comparação da infusão intermitente com a infusão estendida no tratamento do choque séptico de infecções causadas por patógenos gram-negativos com CIM 2-4 mg/L (SILVA JR et al., 2017).

A infusão estendida para os agentes beta-lactâmicos tem sido estratégia recomendada no tratamento de infecções graves nos pacientes sépticos (ABDUL AZIZ et al., 2015). Desta forma, justifica-se o estudo para avaliação do novo alvo terapêutico de $100 \% f \Delta \mathrm{T}>\mathrm{CIM}$ aplicado aos pacientes grandes queimados no período precoce do choque séptico. 


\subsection{Efetividade do Meropenem}

Os compostos carbapenêmicos foram descobertos pela primeira vez em 1976 com a tienamicina, isolada da Streptomyces cattleya, no entanto, a utilidade da tienamicina foi limitada por sua instabilidade química dependente da concentração. Então em 1979, o derivado estável $N$-formimidoyl thienamycin, ou imipenem, foi desenvolvido, sendo um composto extensamente hidrolisado pela desidropeptidase-I (DHP-I) na borda em escova do túbulo renal, com duas consequências importantes: primeiro, a penetração do imipenem na urina o fazendo insuficiente para o tratamento de infecções do trato urinário; em segundo lugar, altas dosagens de imipenem induzem necrose tubular proximal em animais de laboratório. Esses problemas foram superados com a descoberta da cilastatina, um inibidor competitivo reversível de DHP-I, e a associação aumentou a recuperação urinária de imipenem para aproximadamente $60-70 \%$, além de prevenir a nefrotoxicidade (DRUSANO, 1997).

O meropenem, desenvolvido na década de 1980, representou um avanço na química estrutural dos carbapenêmicos, onde a molécula de meropenem possui uma substituição $1 \beta$ metil que fornece estabilidade relativa ao DHP-I, fazendo com que quase 70\% de uma dose de meropenem seja recuperada intacta na urina em 12 horas após a administração, dispensando a co-administração de um inibidor de DHP-I (DRUSANO, 1997; SUNAGAWA, et al., 1990).

Foi lançado com a orientação de uso de $1 \mathrm{~g}$ a cada 8 horas, diluído soro fisiológico ou solução de glicose 5\% e infundido de 20 a 30 min (MEROPENEM, 1995). Difere quimicamente do imipenem por possuir um grupo 1-p-metil na porção carbapenem e uma cadeia lateral 2' substituída que fornece estabilidade à DHP-I. A cadeia lateral 2' de meropenem fornece atividade aprimorada contra P. aeruginosa. Meropenem tem $\mathrm{pK}$, valores de 2,9 e 7,4, e um coeficiente de partição de água de octanol de menos de 1 x 10 - 3 ao longo do intervalo de $\mathrm{pH}$ 3-9. Meropenem tri-hidratado está disponível para uso clínico parenteral como um pó cristalino estéril branco a amarelo, misturado com carbonato de sódio anidro para aumentar sua solubilidade. Os nomes comerciais aprovados para meropenem na época eram Merrem, Meronem, Optinem e Merozen (BLUMER, 1997; PATEL, COOK, 1997)

Quando lançado, apresentou ter atividade contra gram-positivos e patógenos gramnegativos, incluindo anaeróbios, e demonstrou ser mais ativo in vitro do que imipenem contra membros da família Enterobacteriaceae e Pseudomonas aeruginosa (LEROY et al., 1992). No 
entanto, na última década, os relatos de emergência de cepas resistentes de diversos patógenos tem sido crescentes, tendo como possíveis mecanismo de resistência a produção de $\beta$-lactamases, presença de bombas de efluxo, e mutações que alteram as funções das porinas e PBPs (PAPP-WALLACE et al., 2011).

Sendo assim, novas estratégias terapêuticas vêm sendo adotadas visando melhora no desfecho clínico, como a utilização da infusão estendida ou contínua deste agente para o tratamento de infecções graves no paciente séptico (YU et al., 2018). 


\section{OBJETIVO DO ESTUDO}

\section{Objetivo Principal}

Comparar a cobertura da piperacilina/tazobactana e do meropenem no tratamento das infecções causadas por patógenos Gram-negativos após infusão estendida versus infusão intermitente em pacientes sépticos queimados através da abordagem farmacocinéticafarmacodinâmica $(\mathrm{PK} / \mathrm{PD})$.

\section{Objetivos Secundários}

\section{Desfecho farmacocinético}

$>$ Estimativa dos parâmetros farmacocinéticos: taxa de eliminação, meia vida biológica, depuração total corporal e volume de distribuição,

$>$ Avaliar se ocorrem alterações na farmacocinética dos dois antimicrobianos sobinvestigação no período precoce do choque séptico nos pacientes queimados pela comparação aos dados de referência descritos em voluntários sadios.

\section{Desfecho na cobertura dos antimicrobianos contra patógenos hospitalares}

Avaliação da cobertura da piperacilina e do meropenem no novo alvo $100 \% f \Delta \mathrm{T}>\mathrm{CIM}$, $>\quad$ Investigação do impacto das alterações registradas na farmacocinética nos pacientes sobre a cobertura de patógenos, e cura da infecção pelos dois agentes antimicrobianos 


\section{MATERIAL E MÉTODOS}

\subsection{Aspectos Éticos}

O protocolo foi inserido na Plataforma Brasil e aprovado pela CAPPESQ CAAE N. 07525118.3.0000.0068. O termo de consentimento livre esclarecido (TCLE) foi obtido do representante legal de cada paciente incluído no estudo (Apêndice). O representante legal de cada paciente foi informado em detalhes pelo coordenador médico do projeto de investigação sobre o objetivo do estudo e os procedimentos necessários a serem realizados para a consecução do protocolo. Colheu-se a assinatura do termo pelo representante legal de cada paciente e do pesquisador, sendo cada TCLE arquivado na documentação do projeto de estudo no Arquivo de Documentação Médica.

\subsection{Tipos de Comparação e Desfechos}

Realizou-se a comparação de desfecho primário e secundário, a partir de estudo farmacocinético e abordagem PK/PD.

\subsubsection{Desfecho primário}

Desfecho farmacodinâmico: O índice de predição de efetividade estimado para cada paciente da população investigada foi definido pela porcentagem do intervalo de tempo em que o nível sérico da fração livre do antimicrobiano permanece acima da concentração inibitória mínima para o patógeno isolado ( $\% \mathrm{f} \Delta \mathrm{T}>\mathrm{CIM})$. O desfecho farmacodinâmico efetivo considerado foi para o novo alvo de $100 \% f \Delta \mathrm{T}>\mathrm{CIM}$. Porcentagem de pacientes (PTA) que atingiram o alvo terapêutico com a cura clínica e microbiológica. Ressalta-se esse novo alvo considerado no presente estudo foi comparado àqueles reportados em trabalhos anteriores tanto para o Meropenem de $40 \%$ até $60 \% f \Delta \mathrm{T}>\mathrm{CIM}$, quanto para a piperacilina $70 \% f \Delta \mathrm{T}>\mathrm{CIM}$.

\subsubsection{Desfecho secundário}

Desfecho farmacocinético: alteração da farmacocinética de cada antimicrobiano nos pacientes queimados frente aos dados de referência dos estudos conduzidos em voluntários sadios na dose recomendada, após infusão intermitente de $0,5 \mathrm{~h}$ ou infusão estendida de $3 \mathrm{~h}$ para os pacientes sépticos com função renal preservada. 


\subsection{Etapas do Estudo}

O protocolo de estudo foi realizado em três etapas sendo iniciada pela etapa clínica, seguida da analítica e estatística conforme fluxo a seguir:
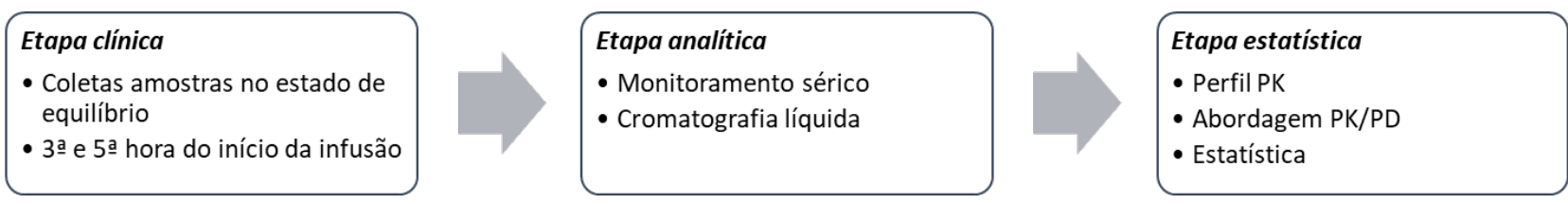

3.3.1 Etapa clínica: Foi conduzida em pacientes grandes queimados em choque séptico com indicação de antimicrobiano beta-lactâmicos, Unidade de Terapia Intensiva de Queimados, Divisão de Cirurgia Plástica e Queimaduras do Instituto Central do Hospital das Clínicas da Faculdade de Medicina da Universidade de São Paulo (HC FMUSP), localizada no $8^{\circ}$ Andar do Instituto Central, Av. Dr. Enéas de Carvalho Aguiar, 255 São Paulo, SP, Brasil.

\section{a) Critérios de elegibilidade e Inclusão de pacientes no estudo}

Quadro 5: Critérios de Inclusão e Exclusão e Exclusão dos Pacientes no Estudo

\begin{tabular}{|ll|}
\hline Critérios de Inclusão & Critérios de Exclusão \\
\hline 1) Pacientes adultos & 1) Pacientes com neutropenia \\
2) Internação na UTIQ & 2) Pacientes com HIV \\
3) Suspeita de choque séptico & 3) Presença de insuficiência renal \\
4) Função renal preservada & 4) Hipersensibilidade ou intolerância \\
5) Prescrição dos $\beta$-lactâmicos & 5) Grávidas ou nutrizes
\end{tabular}

Uma vez preenchidos os critérios de inclusão, o responsável legal foi informado em detalhes sobre o estudo; esclarecidas todas as dúvidas, o responsável legal do paciente forneceu o termo de consentimento livre esclarecido (TCLE) assinado.

Trinta e seis pacientes sépticos adultos de ambos os gêneros, grandes queimados com função renal preservada foram investigados. Estes pacientes permaneceram na Unidade de Terapia Intensiva de Queimados com indicação de terapia antimicrobiana contra patógenos Gram negativos hospitalares com a piperacilina-tazobactana ou o meropenem, os regimes recomendados para a piperacilina-tazobactana 4,5g q6h ou para o meropenem $1 \mathrm{~g} \mathrm{q} 8 \mathrm{~h}$. Ressalta-se que neste protocolo de estudo os pacientes foram estratificados em dois grupos com relação ao tipo de infusão: G1: 18 Pacientes em terapia intensiva do choque séptico recebendo um dos beta-lactâmicos em estudo através de infusão intermitente de 0,5 hora 
conforme recomendação de bula e como critério da CCIH HC FMUSP. Subsequentemente, após a aprovação da emenda pelo CEP iniciou-se a inclusão de pacientes do grupo 2 G2: 18 Pacientes recebendo um dos dois beta-lactâmicos pela infusão estendida de 3 horas na tentativa de melhorar a efetividade destes antimicrobianos.

A função renal de cada paciente em cada seguimento do estudo foi estimada através do clearance da creatinina pela equação de Cockroft-Gault. Estimou-se a superfície corpórea e IMC dos pacientes. As equações para estimativa dos parâmetros são descritas no diagrama.

\begin{tabular}{|c|c|c|c|c|}
\hline \multicolumn{3}{|c|}{$\begin{array}{l}\text { Clearance de creatinina } \\
\text { (CLcr: } \mathrm{mL} / \mathrm{min} \text { ) }\end{array}$} & \multirow{3}{*}{$\begin{array}{l}\text { Índice de massa corpórea } \\
\left(\text { IMC: } \mathrm{kg} / \mathrm{m}^{2}\right)\end{array}$} & \multirow{3}{*}{$S C=\frac{\begin{array}{c}\text { Superfície corpórea } \\
\left(\mathrm{SC}: \mathrm{m}^{2}\right)\end{array}}{\left.1007,2 \times\left(\text { peso }^{2}\right) \times \text { altura }\right]}$} \\
\hline & {$[(140-$ idade $) \times$ peso $]$} & & & \\
\hline CLCr $=$ & $\left(72 x S_{c r}\right)$ & $x F$ & & \\
\hline
\end{tabular}

\section{b) Medicação, regime de dose e administração de antimicrobiano}

A prescrição dos antimicrobianos aos pacientes incluídos no estudo obedeceu ao protocolo anteriormente instituído pelo Grupo de Controle de Infecções Hospitalares (GCIH) versões 2017-2019 e 2019-2021 conforme descrito no "Guia de Utilização de Antimicrobianos e Recomendações para a Prevenção de Infecções Hospitalares do HCFMUSP” 2018-2020.

Quadro 6- Prescrição de agentes beta-lactâmicos na função renal preservada

\begin{tabular}{|c|c|c|}
\hline \multicolumn{2}{|c|}{ Piperacilina/Tazobactam: G1: Intermitente (0,5 h) G2: Estendida (3 h) } \\
\hline Dose diária & Regime de dose & Infusão em bomba \\
\hline $16 \mathrm{~g}$ & $4,5 \mathrm{~g}$ q6h & G1 e G2 \\
\hline Meropenem: G1: Intermitente (0,5 h) G2: Estendida (3 h) & \\
\hline Dose diária & Regime de dose & Infusão em bomba \\
\hline $3 \mathrm{~g}$ & $1 \mathrm{~g} \mathrm{q} 8 \mathrm{~h}$ & $\mathrm{G} 1$ e G2 \\
\hline
\end{tabular}

\section{c) Coleta de amostras de sangue para controle terapêutico do $\beta$-lactâmico}

Efetuou-se a coleta de duas amostras sanguíneas $(1,5 \mathrm{~mL}$ cada/tubo gel) de cateter venoso central pela enfermeira ou pelo médico intensivista, sendo a primeira coleta realizada na $3^{\mathrm{a}}$ hora após o início da infusão, e a segunda coleta na $5^{\mathrm{a}}$ após o início da infusão. As 
amostras foram devidamente identificadas e transportadas sob refrigeração no mesmo dia para o laboratório do Centro de Farmacocinética Clínica, FCF USP.

d) Coleta de dados dos pacientes: as informações clínicas e demográficas dos pacientes foram obtidas do prontuário médico físico e eletrônico do hospital. A rotina exames laboratoriais nos pacientes da UTI foram realizados pela Divisão de Laboratório Central (DLC) do hospital. Os resultados dos exames foram capturados da rede Intranet HC-MED na admissão e na data da coleta de sangue para dosagem sérica e abordagem PK/PD.

\section{Fluxo de Coleta de Dados dos Pacientes}

Perfil clínico de admissão: Idade, peso, altura, superfície corporal total queimada (SCTQ), escore de gravidade na admissão SAPS3 e risco de morte do paciente, presença de lesão inalatória, ventilação mecânica e necessidade de vasopressores.

Exames laboratoriais de rotina - pacientes de UTI: Hemograma completo, eletrólitos (sódio, potássio, cálcio total e iônico, magnésio, fósforo, cloro) lactato arterial (biomarcador de perfusão tecidual), proteína C-reativa (PCR), leucócitos e neutrófilos, gasometria arterial (saturação de $\mathrm{O}_{2}$ ), creatinina sérica, uréia sérica, tempo de tromboplastina parcial ativado (TTPa) e tempo de protrombina (TP), plaquetas.

Microbiologia: Culturas de fluidos e secreções (sangue periférico, lavado de ferida, lavado broncoalveolar, urina). Isolamento dos patógenos e realização do teste de sensibilidade do patógeno causador da infecção ao antimicrobiano para estimativa da concentração inibitória mínima (CIM).

Anamnese e evolução clínica: Evolução médica (24 horas) e Prescrição médica no seguimento clínico-laboratorial desde o início da terapia antimicrobiana até a cura clínica e microbiológica.

3.3.2 Etapa analítica: Realizada no Centro de Farmacocinética Clínica do Laboratório de Farmacologia Terapêutica, Bloco 13B $1^{\circ}$ piso, Faculdade de Ciências Farmacêuticas da Universidade de São Paulo, Avenida Professor Lineu Prestes 580, campus da Capital. Constitui-se de análise quantitativa das amostras sanguíneas dos agentes $\beta$-lactâmicos, Piperacilina e Meropenem, via cromatografia líquida de alta eficiência (CLAE) pelo método de padrão interno, ilustrados em fluxogramas independentes.

\section{a) Monitoramento sérico de beta-lactâmicos nos pacientes grandes queimados}

Cada paciente recebeu número de alocação, ordem sequencial, com o registro de entrada das matrizes no Laboratório Bioanalítico e as amostras de sangue para dosagem sérica de $\beta$-lactâmico deram entrada no Livro de Registro de Dosagem Sérica de AntimicrobianosAntifúngicos do laboratório.

As amostras foram processadas de acordo com o procedimento operacional padrão (POP analítico) do laboratório e quantificadas através de CLAE, que permitiu a realização do monitoramento sérico do antimicrobiano, e então realizou-se a modelagem farmacocinética seguida da avaliação da cobertura do antimicrobiano pela abordagem PK/PD para cada paciente em terapia do choque séptico. 


\section{Fluxograma 1 - Método Bioanalítico da Piperacilina Sérica}

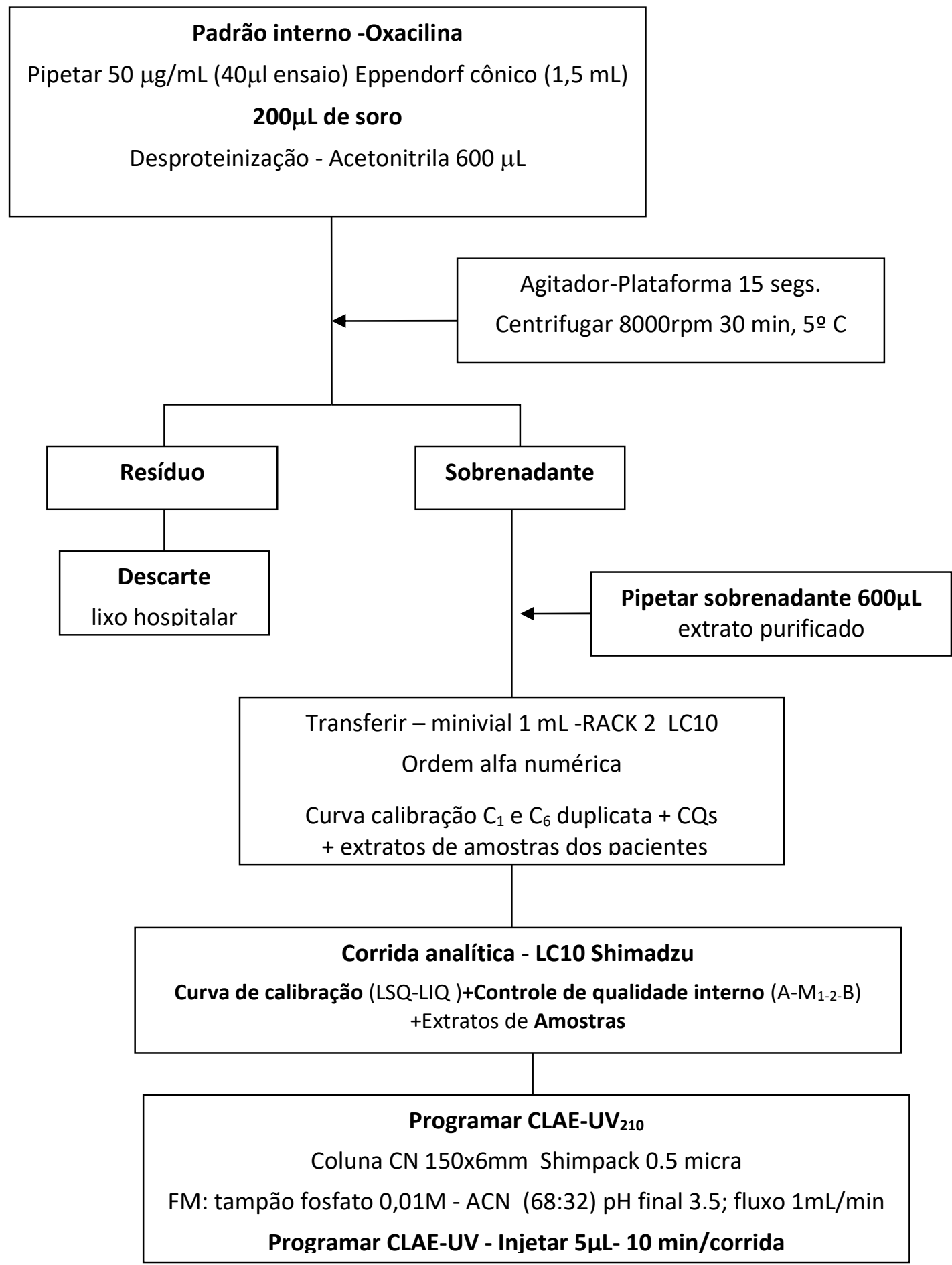

SANCHES-GIRAUD et al., (2010) 
Fluxograma 2 - Método bioanalítico do Meropenem Sérico.

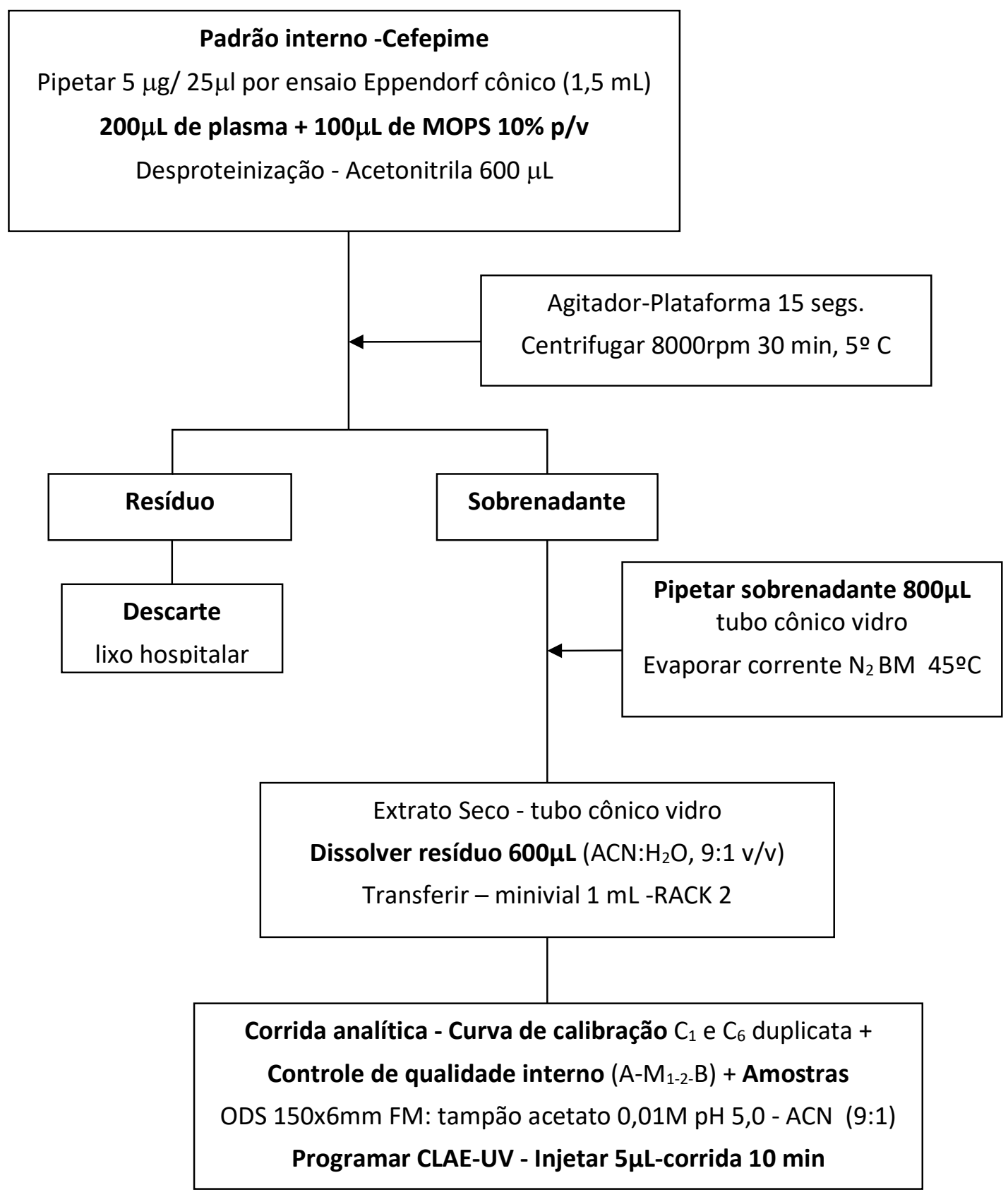

SANTOS et al. (2011) 
3.3.3 Etapa estatística: Realizada no Centro de Farmacocinética Clínica do Laboratório de Farmacologia Terapêutica, Bloco 13B $1^{\circ}$ piso, Faculdade de Ciências Farmacêuticas da Universidade de São Paulo, Avenida Professor Lineu Prestes 580, campus da Capital.

a) Farmacocinética: taxa de eliminação, meia vida biológica, depuração total corporal e extensão da distribuição estimada através do parâmetro volume aparente de distribuição descritos no diagrama abaixo.

\begin{tabular}{|c|c|c|}
\hline Parâmetro & Unidade & Equação \\
\hline Taxa de infusão & $\mathrm{ko}(\mathrm{mg} / \mathrm{h})$ & Dose/Tinfusão \\
\hline Taxa de eliminação & $\mathrm{kel}\left(\mathrm{h}^{-1}\right)$ & $\left(\mathrm{LnC}_{1}-\mathrm{LnC}_{2}\right) /\left(\mathrm{T}_{1}-\mathrm{T}_{2}\right)$ \\
\hline Meia vida biológica & $\mathrm{t}_{(1 / 2) \beta}(\mathrm{h})$ & $0,693 / \mathrm{kel}$ \\
\hline Área sob a curva/platô & $\mathrm{ASC}_{\tau}^{\text {ss }}(\mathrm{mg} . \mathrm{h} / \mathrm{L})$ & Trapezóides \\
\hline Depuração total corporal & $\mathrm{CL}_{\mathrm{T}}(\mathrm{L} / \mathrm{h})$ & Dose tid/ $\mathrm{ASC}_{\tau}{ }^{\text {ss }}$ \\
\hline Volume aparente de distribuição & $\mathrm{Vd}^{\text {ss }}(\mathrm{L})$ & Dose $/\left(\mathrm{kel} . \mathrm{ASC}_{\tau}{ }^{\text {ss }}\right)$ \\
\hline
\end{tabular}

Abreviaturas: $\mathrm{t}_{(1 / 2) \beta}$ : meia vida biológica; $\mathrm{CL}_{\mathrm{T}}$ : depuração plasmática; $\mathrm{Vd}^{\mathrm{ss}}$ : volume aparente de distribuição.

\section{b) Estimativa do índice de predição de efetividade através da abordagem PK/PD}

O aumento da resistência bacteriana tem sido registrado para o regime de dose empírico recomendado para diversos antimicrobianos em consequência da alteração da farmacocinética desses agentes terapêuticos nos pacientes críticos. Considera-se ainda que essa resistência dependa do conhecimento da atividade do antimicrobiano e da sensibilidade do patógeno ao agente terapêutico. Então, a aplicação da abordagem PK/PD permite correlacionar o perfil farmacocinético do antimicrobiano (medida in vivo) com a sensibilidade do patógeno ao agente antimicrobiano (CIM) fornecida pela medida in vitro, permitindo a estimativa do índice de predição da efetividade de cada antimicrobiano contra o patógeno hospitalar sensível isolado. Então, foi estimado um índice para predição da efetividade para cada agente terapêutico do estudo representado no diagrama geral da efetividade de antimicrobianos. $\mathrm{O}$ cálculo do índice de predição de efetividade dos dois beta-lactâmicos foi realizado para a avaliação da cobertura do antimicrobiano contra os patógenos isolados na população de pacientes críticos. Esse índice foi estimado para os beta-lactâmicos com base na expressão $\% f \Delta \mathrm{T}>\mathrm{CIM}$, levando-se em conta os parâmetros da farmacocinética (vale sérico, taxa de eliminação) e da farmacodinâmica (CIM: concentração inibitória mínima bactericida). O novo alvo PK/PD de $100 \% f \Delta \mathrm{T}>\mathrm{CIM}$ foi considerado para os dois beta-lactâmicos investigados; uma vez que a efetividade destes agentes é tempo dependente (ABDUL-AZIZ et al., 2016). Torna-se importante destacar que a concentração inibitória mínima (CIM) é um dado 
farmacodinâmico obtido in vitro e é determinada rotineiramente após o isolamento do patógeno pelo Setor_de Microbiologia da DLC e emissão de resultados pela rede para os pacientes internados nas UTIs do hospital. Destaca-se que a base de dados utilizada neste laboratório é o Clinical \& Laboratory Standard Institute (CLSI).

c) Tratamento estatístico: A estatística descritiva foi realizada a partir dos dados individuais, e expressa em dados populacionais obtidos dos testes estatísticos. Utilizou-se o Office PowerPoint e Office Excell 365 (Microsoft Corporation, USA) e o GraphPad Prism for Windows 5.0, GraphPad Software Inc. (San Diego, CA, USA). Na estatística descritiva, os dados populacionais foram expressos através de mediana (interquartis), e no estudo de correlação linear expressos pelo coeficiente de correlação $\left(\mathrm{r}^{2}\right)$. A avaliação quantitativa foi obtida pela aplicação de teste de Mann-Whitney; enquanto que as proporções foram avaliadas pelo teste de contingência de Fisher. A significância estatística de $p<0,05$ foi considerada. A cobertura dos antimicrobianos contra os patógenos isolados dos pacientes críticos em terapia intensiva foi ilustrada graficamente utilizando o Prism dot, GraphPad Prism for Windows v_5.0.

\section{d) Estudo de desfecho}

Avaliou-se o tempo de internação em UTI, o período de internação, a cura clínica, necessidade de escalonamento do antimicrobiano, número de altas e baixas hospitalares.

\section{e) Gerenciamento dos dados e arquivos para rastreabilidade}

Consideraram-se os arquivos a) Prontuário Médico, b) Evolução Clínica, c) Prescrição Médica, d) Resultados de Exames, de qualquer natureza, e) TCLE como "documentos-fonte", de onde foram retirados os dados necessários ao estudo. Todos os documentos-fonte do paciente ficaram retidos e arquivados no arquivo médico do HC FMUSP, sob responsabilidade e de acordo com a legislação médica vigente. $\mathrm{O}$ banco de dados gerado pelo estudo, como os documentos relatórios (cartas de comunicação com o CEP), e qualquer outra documentação com dados do estudo (tabelas, gráficos, cromatogramas) foram arquivados em via original ou cópia (conforme aplicável) em local seguro do Laboratório Bionalítico. Tal medida tem como finalidade garantir a rastreabilidade da documentação do projeto e dos dados obtidos.

f) Confidencialidade dos dados coletados: Assinando o Termo de Consentimento Livre e Esclarecido do estudo, o paciente/representante legal atesta que tem ciência de que os dados 
coletados a partir de sua participação puderam ser tornados públicos. Porém, como preconiza a legislação de pesquisa clínica vigente (RDC 205/17), durante e após a realização do estudo, os pacientes envolvidos foram identificados unicamente através de suas iniciais e por seu código de alocação no estudo. Em caso de publicação, a identidade de todo e qualquer paciente envolvido no estudo serão mantidas em sigilo. 


\section{RESULTADOS}

\subsection{Casuística}

Investigaram-se 36 pacientes adultos sépticos queimados com função renal preservada, ambos os gêneros $(12 \mathrm{~F} / 24 \mathrm{M})$, em terapia intensiva do choque séptico com os agentes antimicrobianos piperacilina-tazobactam $4 \mathrm{~g} q 6 \mathrm{~h}$ ou meropenem $1 \mathrm{~g} \mathrm{q} 8 \mathrm{~h}$. Os pacientes incluídos no estudo foram estratificados em dois grupos com base no tempo da administração da infusão, podendo ser classificados como intermitente de 0,5 h (G1) ou da infusão estendida de $3 \mathrm{~h}(\mathrm{G} 2)$, conforme indicado a seguir:

\begin{tabular}{l|l|c|c|c|}
\cline { 2 - 5 } \multirow{2}{*}{$\begin{array}{l}\text { Alocação dos } 36 \\
\text { pacientes }\end{array}$} & \multicolumn{2}{|c|}{ Piperacilina $4 \mathrm{~g}$ q6h } & \multicolumn{2}{c|}{ Meropenem 1g q8h } \\
\cline { 2 - 5 } & $\begin{array}{l}\text { Infusão } \\
0,5 \mathrm{~h}\end{array}$ & $\begin{array}{c}\text { Infusão } \\
3 \mathrm{~h}\end{array}$ & $\begin{array}{c}\text { Infusão } \\
0,5 \mathrm{~h}\end{array}$ & $\begin{array}{c}\text { Infusão } \\
3 \mathrm{~h}\end{array}$ \\
\hline $\begin{array}{l}\text { Infusão intermitente: G1 } \\
\mathrm{N} 1=18\end{array}$ & 8 pacientes & & 10 pacientes & \\
\hline $\begin{array}{l}\text { Infusão estendida: G2 } \\
\mathrm{N} 2=18\end{array}$ & & 10 pacientes & & 8 pacientes \\
\hline
\end{tabular}

A elegibilidade dos pacientes obedeceu aos critérios de inclusão/exclusão definidos com o seguinte tamanho amostral, como ilustrado no diagrama de fluxo.
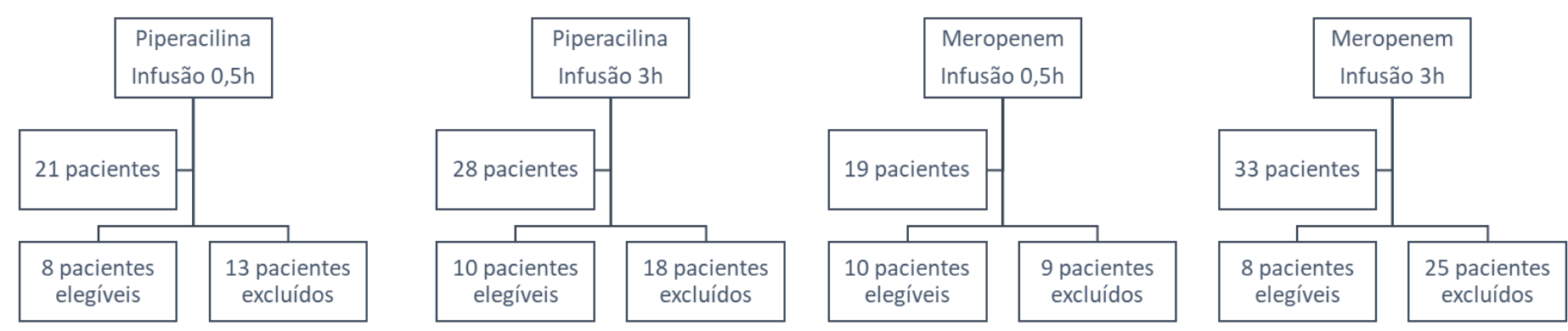
Os dados demográficos dos pacientes incluídos são descritos na tabela 1.

Tabela 1 - Característica demográficas dos pacientes investigados

\begin{tabular}{|c|c|c|c|}
\hline & Grupo $1(0,5 h)$ & G2 (3h) & Estatística \\
\hline Gênero & $16 \mathrm{M} / 2 \mathrm{~F}$ & $13 \mathrm{M} / 5 \mathrm{~F}$ & $0.4018^{(*)}$ \\
\hline Idade (anos) & $30(24-31)$ & $27(24-34)$ & $0.9620^{(* *)}$ \\
\hline Peso ideal (Kg) & $70(57-75)$ & $73(55-79)$ & $0.5986^{(* *)}$ \\
\hline Peso real (Kg) & $70(61-75)$ & $71(65-75)$ & $0.5926^{(* *)}$ \\
\hline Altura (cm) & 171(166-177) & $173(165-179)$ & $0.5983^{(* *)}$ \\
\hline $\mathrm{SC}\left(\mathrm{m}^{2}\right)$ & $1,82(1,58-1,89)$ & $1,87(1,60-2,00)$ & $0.9397^{(* *)}$ \\
\hline IMC $\left(\mathrm{Kg} / \mathrm{m}^{2}\right)$ & $24(22-25)$ & $24(20-25)$ & $0.9369^{(* *)}$ \\
\hline
\end{tabular}

Abreviaturas - M: masculino; F: feminino; SC: Superfície Corpórea; NAP: não aplicável. Estatística: Mann Whitney**; Teste de Contingência de Fisher*. Significância estatística p $<0,05$.

As características de admissão dos pacientes grandes queimados investigados são demonstradas na figura 1. Não se evidenciou também diferença significativa entre grupos após o teste de contingência de Fisher relativamente lesão inalatória, tipo de trauma térmico ou elétrico sofrido pelos pacientes das duas populações investigadas. Entretanto, registrou-se diferença estatística entre grupos quando se comparou em G1/G2, a necessidade de ventilação mecânica em 16/9 e de vasopressores em 15/8. Também não se observou diferença significativa entre grupos com relação à superfície corpórea total queimada, escore SAPS 3 de admissão na UTI, o respectivo risco de morte associado.

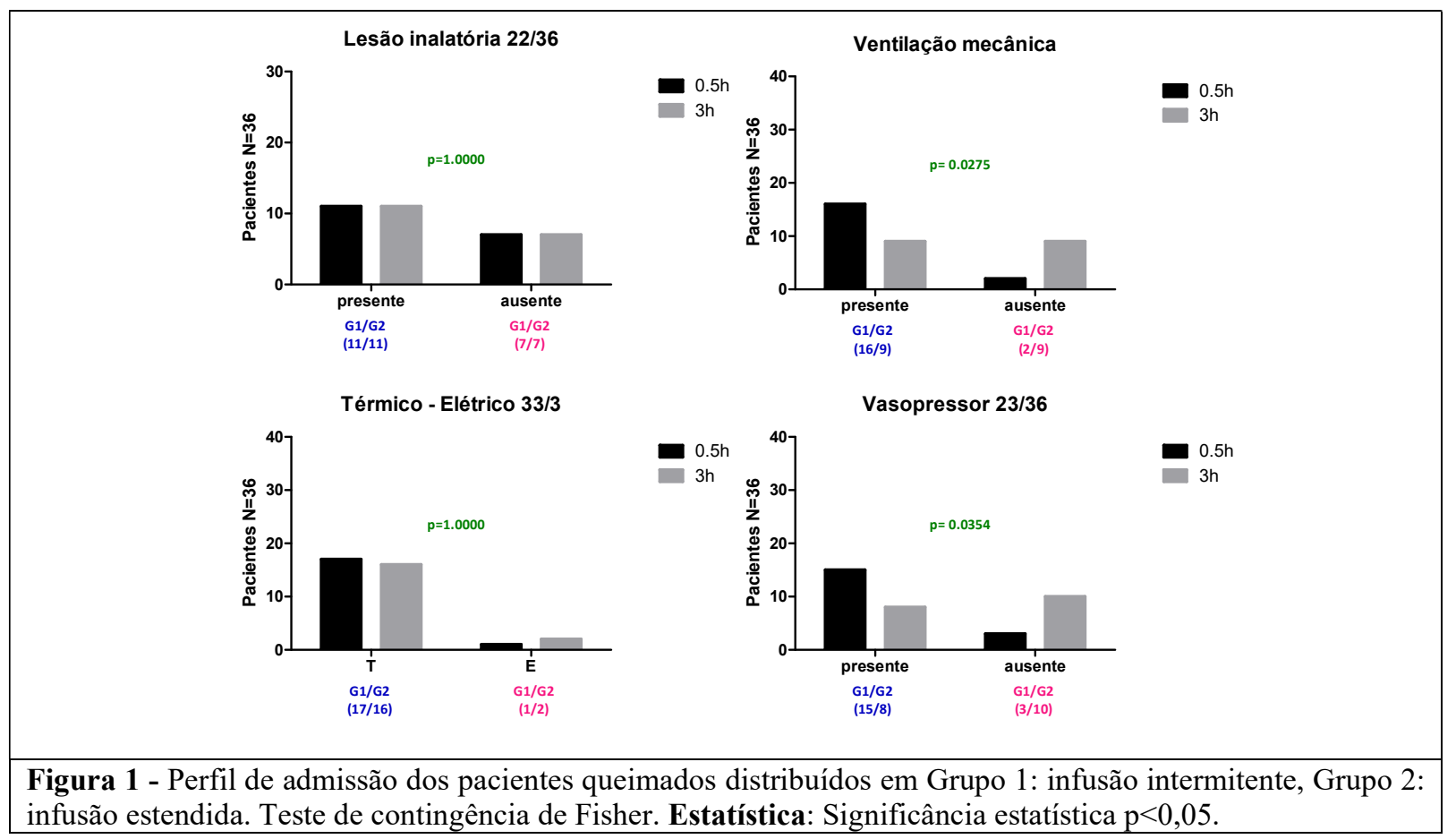


Realizou-se a comparação entre grupos para a superfície corpórea total queimada e para o escore de admissão dos pacientes na UTI como ilustrado nas figuras 2 e 3 respectivamente. Realizou-se ainda a estratificação da $\mathrm{SCTQ}<40 \%, \mathrm{SCTQ}>40 \%$ e do SAPS $3<57$ e SAPS $3>57$, Figuras 2 e 3 .

\section{$\mathbf{A}$}

B
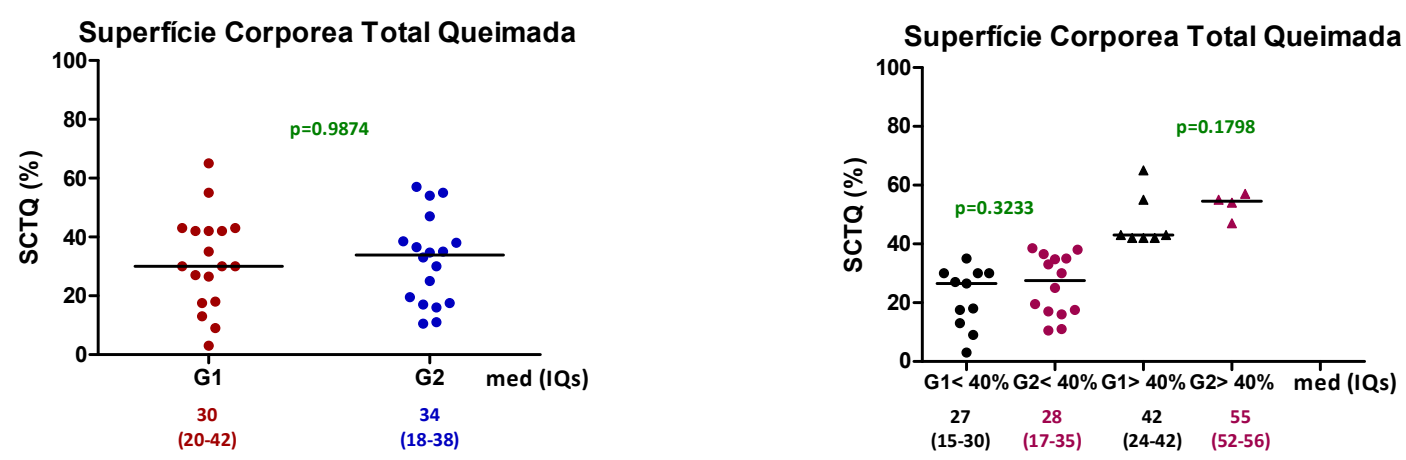

Figura 2 - Superfície corpórea total queimada avaliada na admissão dos pacientes na UTI (A) Comparação entre grupos G1 x G2; (B) Estratificação da SCTQ e comparação G1 x G2

A
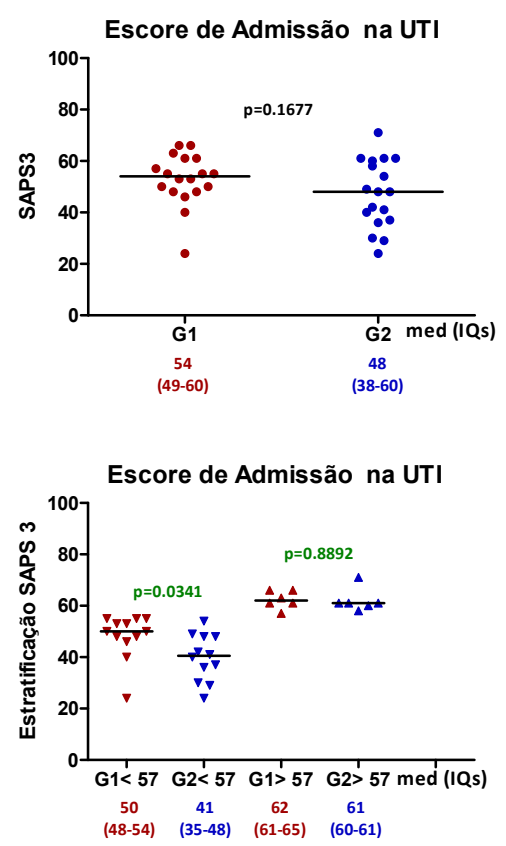

B
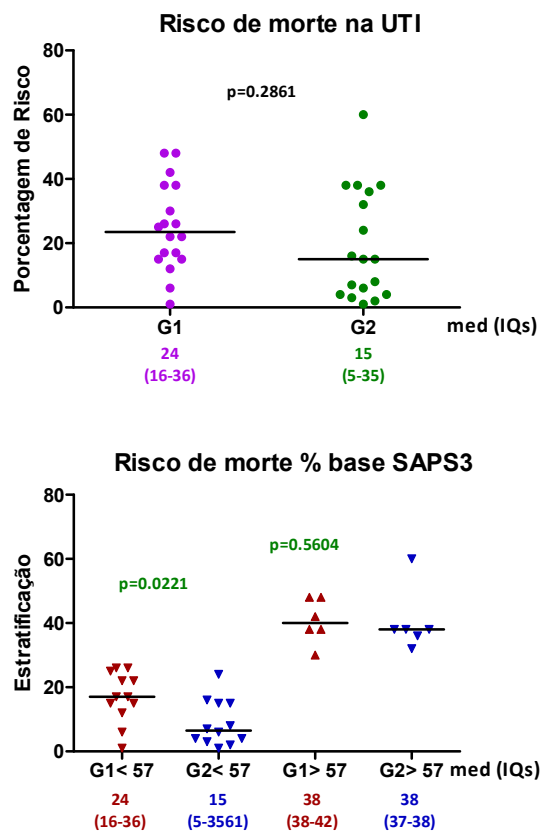

Figura 3 - Escore de gravidade na admissão dos pacientes na UTI G1 versus G2

Painel superior: Comparação G1 versus G2 (A) SAPS 3 (B) Risco de morte associado

Painel inferior: Estratificação comparada (A) SAPS 3 e (B) Risco de morte associado 
A comparação dos grupos não evidenciou diferença significativa relativa à SCTQ, SAPS3 e risco de morte associado à gravidade do paciente admitido na UTI.

Entretanto, pela estratificação do escore evidenciou-se diferença entre grupos relativamente ao SAPS $3<57$ e o respectivo risco de morte associado.

Os dados populacionais para os pacientes dos grupos 1 e 2 são descritos para a superfície corpórea total queimada e para o escore de admissão dos pacientes na UTI, SAPS 3 e o respectivo risco de morte associado. Os grupos foram comparados através do Teste de Mann Whitney, e pelo teste de contingência de Fisher na comparação entre as proporções.

O perfil laboratorial de biomarcadores obtido pela admissão do paciente na UTI é descrito na Tabela 2; ressalta-se que não se registrou diferença entre grupos.

Tabela 2 - Perfil laboratorial de biomarcadores na Admissão dos Pacientes

\begin{tabular}{|c|c|c|c|c|}
\hline Biomarcador & $\begin{array}{c}\text { Valor } \\
\text { Referência }\end{array}$ & $\begin{array}{c}G 1 \\
N_{1}=18\end{array}$ & $\begin{array}{c}G 2 \\
N_{2}=18\end{array}$ & Estatística \\
\hline $\begin{array}{c}\mathrm{Scr} \\
(\mathrm{mg} / \mathrm{dL})\end{array}$ & $<1,4$ & $\begin{array}{c}0,83 \\
(0,68-1,16)\end{array}$ & $\begin{array}{c}0,90 \\
(0,60-1,20)\end{array}$ & 0.8743 \\
\hline $\begin{array}{c}\text { CLcr } \\
(\mathrm{mL} / \mathrm{min})\end{array}$ & $90-120$ & $\begin{array}{c}115 \\
(83-148) \\
\end{array}$ & $\begin{array}{c}127 \\
(90-170) \\
\end{array}$ & 0.6463 \\
\hline $\begin{array}{c}\text { PCR } \\
(\mathrm{mg} / \mathrm{L})\end{array}$ & $<5$ & $\begin{array}{c}232 \\
(107-285) \\
\end{array}$ & $\begin{array}{c}183 \\
(118-279) \\
\end{array}$ & 0.9747 \\
\hline $\begin{array}{c}\text { Leucócitos } \\
\left(\mathbf{m i l} \text { cel } / \mathbf{m m}^{3}\right)\end{array}$ & 4 a 11 & $\begin{array}{c}10,91 \\
(4,60-13,93) \\
\end{array}$ & $\begin{array}{c}14,05 \\
(11,47-18,10) \\
\end{array}$ & 0.0302 \\
\hline $\begin{array}{l}\text { Neutrófilos } \\
\left(\mathrm{mil} \text { cel } / \mathbf{m m}^{3}\right)\end{array}$ & 1,6 a 7,0 & $\begin{array}{c}8,55 \\
(3,40-11,22)\end{array}$ & $\begin{array}{c}10,28 \\
(8,91-15,77)\end{array}$ & 0.0576 \\
\hline
\end{tabular}

Abreviaturas: Clcr: clearance da creatinina; PCR: proteína $\mathrm{C}$ reativa.

Estatística: Mann Whitney, significância estatística $\mathrm{p}<0,05$; mediana (interquartil).

Fontes: [1] Fleury (2018); [2] Cockroft \& Gault (1976) 
A terapia empírica do choque séptico foi realizada pela administração de piperacilinatazobactana ou do meropenem nas doses recomendadas a critério da equipe médica da UTI, conforme descrito nas Tabelas 3 e 4, respectivamente.

Tabela 3- Terapia empírica do choque séptico com Piperacilina-Tazobactana 4,5g q6h infusão intermitente 0,5 hora versus infusão estendida 3 horas

\begin{tabular}{c|c|c|c|c|c|c}
\hline & & \multicolumn{2}{|c|}{ Grupo 1 n=8 } & \multicolumn{2}{c|}{ Grupo 2 n=10 } & ESTATÍSTICA \\
\hline & Unidade & Mediana & (interquartis) & Mediana & (interquartis) & Mann Whitney \\
\hline Dose/dia & $\begin{array}{c}\mathrm{mg} / \mathrm{kg} \\
\text { dia }\end{array}$ & 229 & $(217-297)$ & 225 & $(214-246)$ & 0.5620 \\
\hline Dose/ $\tau$ & $\begin{array}{c}\mathrm{mg} / \mathrm{kg} \\
\text { dose }\end{array}$ & 57 & $(54-74)$ & 62 & $(51-72)$ & 0.6236 \\
\hline $\mathbf{A S C}^{\mathbf{s s}} \mathbf{0 - 2 4}$ & $\mathrm{mg}{ }^{*} \mathrm{~h} / \mathrm{L}$ & 1831 & $(1778-1886)$ & 1447 & $(1156-1572)$ & 0.0085 \\
\hline $\mathbf{A S C}^{\mathbf{s s}} \tau$ & $\mathrm{mg} / \mathrm{h} / \mathrm{L}$ & 458 & $(444-471)$ & 362 & $(289-393)$ & 0.0085 \\
\hline Vale & $\mathrm{mg} / \mathrm{L}$ & 4,8 & $(4,1-5,8)$ & 32,1 & $(26,0-33,2)$ & 0.0004 \\
\hline
\end{tabular}

Abreviaturas: ASC ss: Área Sob Curva no estado de equilíbrio; $\tau$ : "tau" intervalo de dose

Estatística: Teste Mann Whitney, significância $p<0,05$

Com base nos níveis de vale séricos obtidos para a piperacilina após infusão intermitente ou infusão estendida, evidenciou-se diferença significativa entre grupos apesar da administração de doses semelhantes aos pacientes queimados em terapia intensiva. Adicionalmente, a disponibilidade sistêmica medida através da área sob a curva obtida para a piperacilina após infusão intermitente ou infusão estendida, evidenciou-se diferença significativa entre grupos após administração de doses semelhantes aos pacientes sépticos grandes queimados.

Tabela 4 - Terapia empírica do choque séptico Meropenem 1g q8h, infusão intermitente 0,5 hora $x$ infusão estendida 3 horas

\begin{tabular}{c|c|c|c|c|c|c}
\hline & & \multicolumn{2}{|c|}{ Grupo 1 n=10 } & \multicolumn{2}{c|}{ Grupo 2 n=8 } & ESTATÍSTICA \\
\hline & Unidade & Mediana & (interquartis) & Mediana & (interquartis) & Mann Whitney \\
\hline Dose/dia & $\mathbf{m g / k g ~ d i a ~}$ & 41 & $(40-43)$ & 41 & $(38-45)$ & 0.3491 \\
\hline $\mathbf{D o s e} / \tau$ & $\mathbf{m g} / \mathbf{k g ~ d o s e}$ & 14 & $(13-14)$ & 14 & $(13-15)$ & 0.6222 \\
\hline $\mathbf{A S C}^{\mathbf{s s}} \mathbf{0 - 2 4}$ & $\mathbf{m g * h} / \mathbf{L}$ & 568 & $(558-597)$ & 338 & $(335-347)$ & 0.0004 \\
\hline $\mathbf{A S C}^{\mathbf{s s}} \tau$ & $\mathbf{m g * h} / \mathbf{L}$ & 189 & $(186-199)$ & 84 & $(84-87)$ & 0.0004 \\
\hline Vale & $\mathbf{m g} / \mathbf{L}$ & 3,2 & $(2,6-4,2)$ & 7,3 & $(7,0-8,0)$ & 0.0009 \\
\hline
\end{tabular}

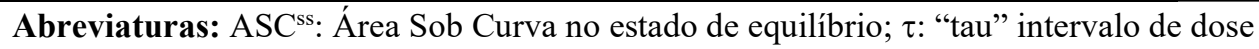

Estatística: Teste Mann Whitney, significância $p<0,05$ 
Da mesma forma, com base nos níveis de vale séricos de meropenem, e a disponibilidade sistêmica medida através da área sob a curva após infusão intermitente ou infusão estendida, evidenciou-se diferença significativa entre grupos após administração de doses comparáveis aos pacientes sépticos grandes queimados. A dose diária e o regime de dose normalizada com o peso corporal ideal, e o vale sérico para os dois beta-lactâmicos são ilustrados na Figura 4.

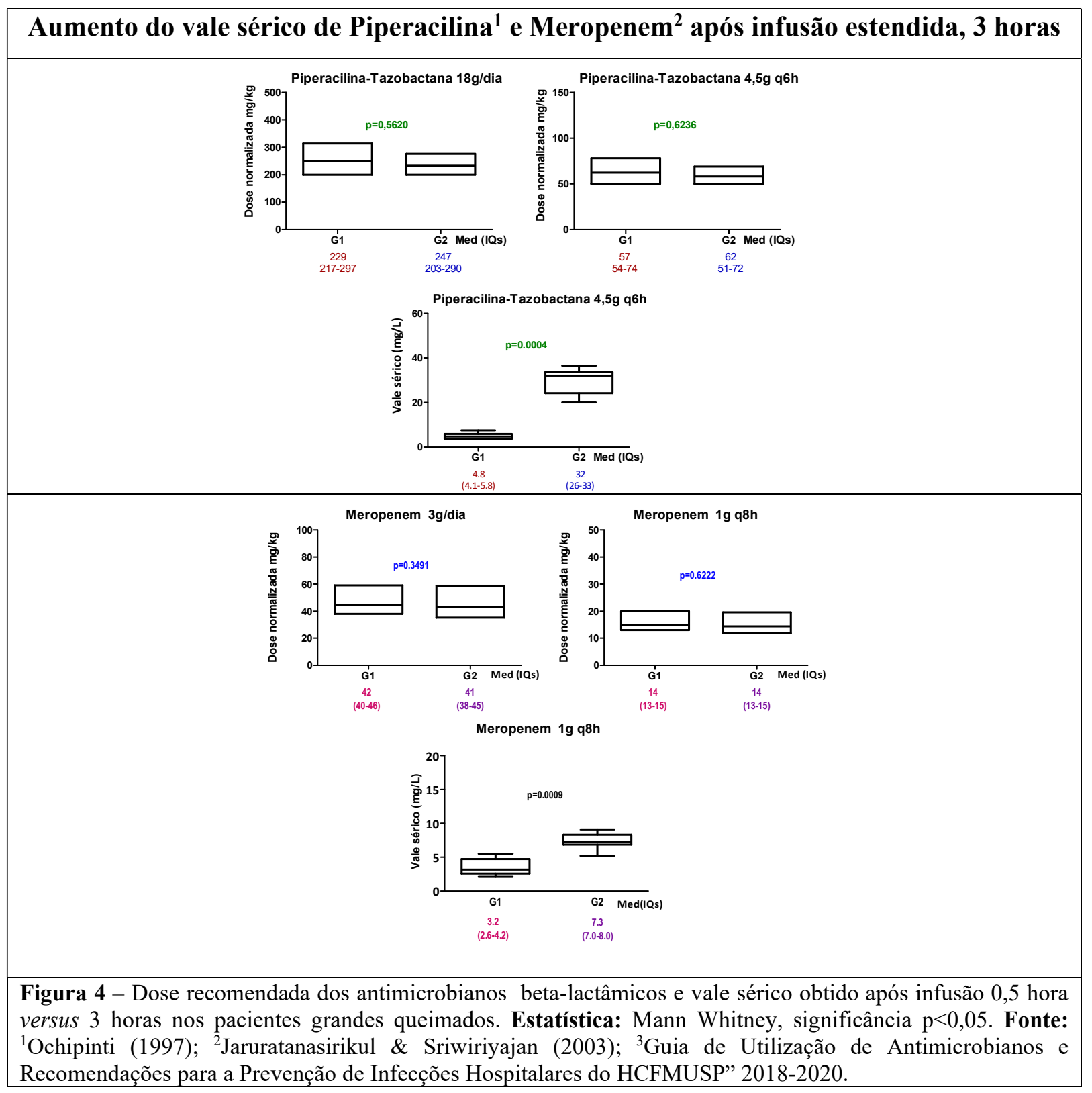


Registrou-se o prolongamento da meia vida decorrente do aumento do volume de distribuição para os dois beta-lactâmicos após a infusão estendida versus intermitente. Então, as alterações da farmacocinética registradas para cada agente terapêutico após a infusão intermitente versus estendida foram comparadas aos valores de referência descritos para voluntários sadios, ilustradas na Figura 5 para a piperacilina.

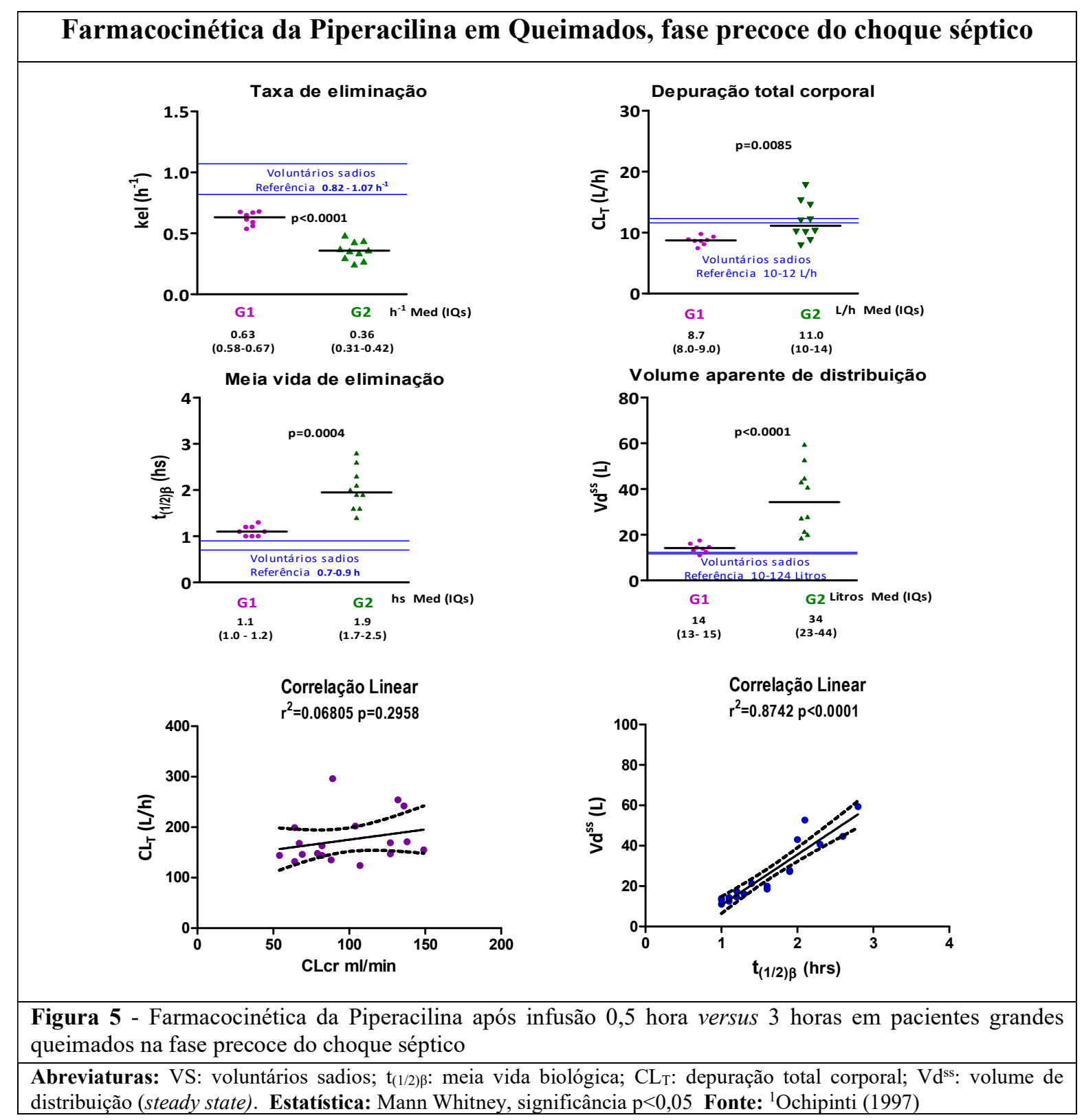

Apesar disso, registrou-se diferença significativa entre grupos para a piperacilina após infusão estendida versus intermitente, com redução da taxa de eliminação, e prolongamento da meia vida decorrente do aumento do volume aparente de distribuição; evidenciou-se correlação linear entre a meia vida e o volume aparente. 
As alterações da farmacocinética registradas para o meropenem após a infusão intermitente versus estendida foram comparadas aos valores de referência descritos para voluntários sadios, ilustradas na Figura 6.

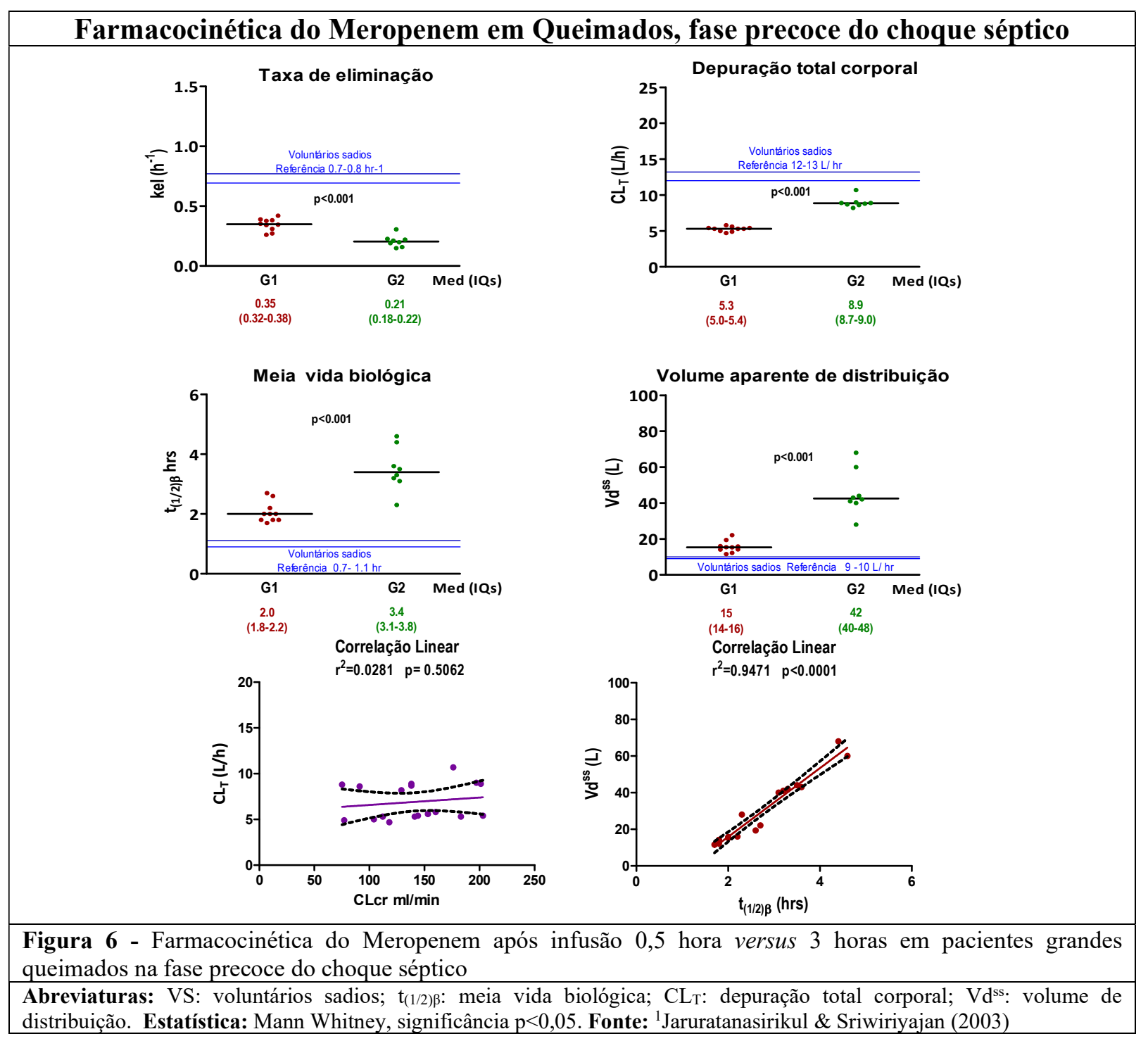

Frente à faixa de referência definida para voluntários sadios, os dois grupos de pacientes incluídos no G1 e no G2 evidenciaram alteração na farmacocinética do meropenem. Além disso, registrou-se diferença significativa entre grupos para o carbapenêmico após infusão estendida comparada à infusão intermitente. Evidenciou-se redução da taxa de eliminação e o prolongamento da meia vida decorrentes do aumento do volume aparente de distribuição. Foi possível estabelecer correlação linear entre a meia vida e o volume aparente, com alto coeficiente de correlação, $\mathrm{r} 2=0,9471$. Não se evidenciou correlação entre o clearance da creatinina e a depuração total corporal para os dois beta-lactâmicos. 
A cobertura antimicrobiana após infusão intermitente versus infusão estendida das doses recomendadas e prescritas aos pacientes sépticos grandes queimados ocorreu para o alvo $\mathrm{PK} / \mathrm{PD}$ considerado $100 \% \mathrm{f}>\mathrm{CIM}$, ilustrada para piperacilina e meropenem, Figura 7
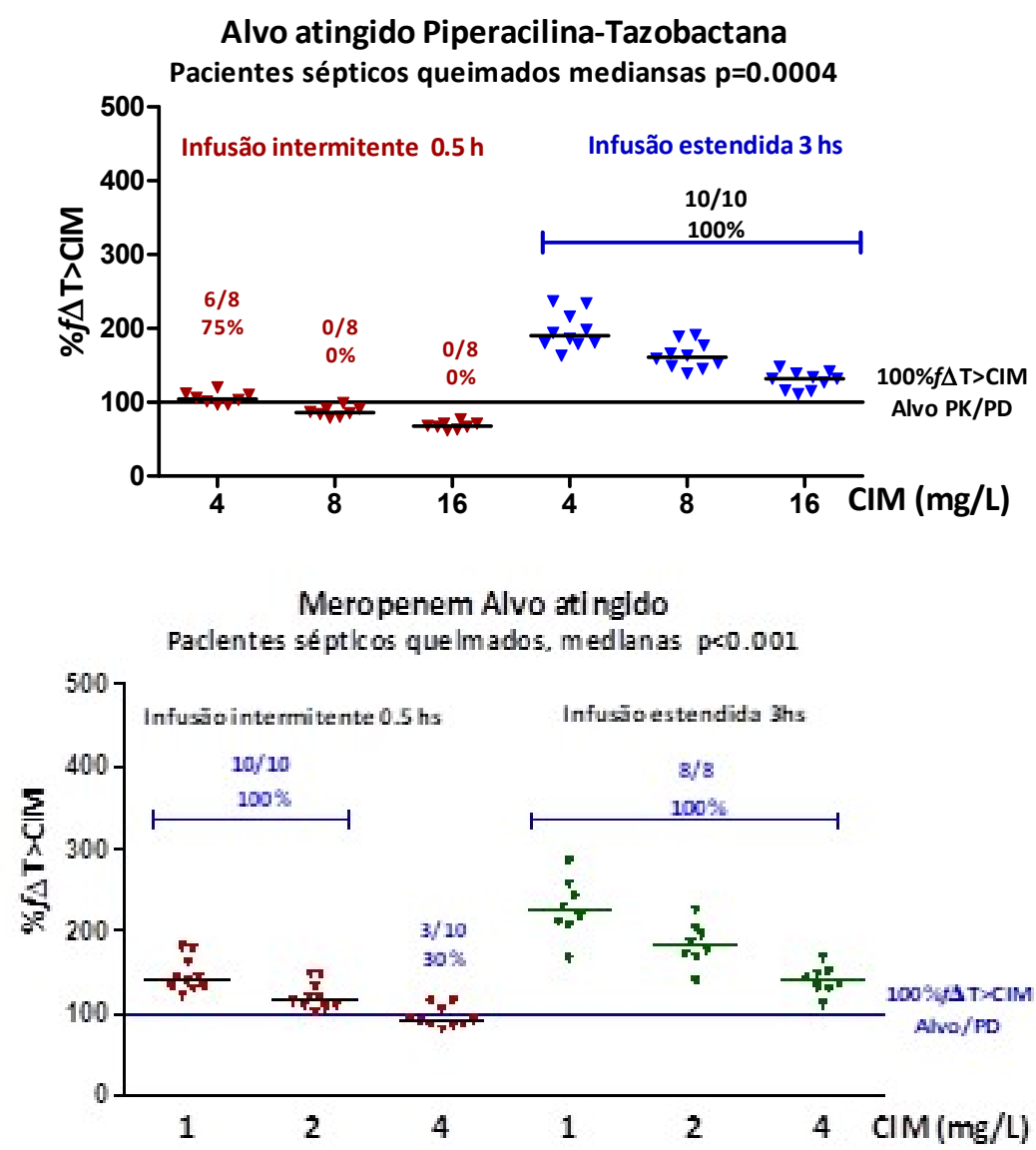

Figura 7 - Cobertura de beta-lactâmicos após infusão intermitente versus estendida nos pacientes grandes queimados, fase precoce do primeiro choque séptico

Abreviaturas: \% $\mathrm{f} \Delta \mathrm{T}>\mathrm{CIM}$ índice de predição de efetividade; $100 \% \% f \Delta \mathrm{T}>\mathrm{CIM}$ : Alvo $\mathrm{PK} / \mathrm{PD}$ para a piperacilina e meropenem Estatística: Mann Whitney, significância p $<0,05$; Prism 5.0

Evidenciou-se a superioridade da infusão estendida de 3 horas comparada à infusão intermitente de 0,5 hora, para os dois beta-lactâmicos sob investigação nos pacientes queimados.

A cura clínica foi registrada no G1 em apenas 1/8 paciente tratado com a piperacilina após infusão intermitente, uma vez que o antimicrobiano escalonado foi substituído pelo meropenem, infusão intermitente, com a cura das infecções causadas por Gram negativos isolados até CIM $2 \mathrm{mg} / \mathrm{L}$. Em contrapartida, a piperacilina promoveu a cura clínica de 4/10 pacientes do G2 que receberam infusão estendida de piperacilina. Desta forma, uma vez escalonada, ela foi substituída pelo meropenem nos demais pacientes (6/10). A cura 
microbiológica pela piperacilina ocorreu em quatro pacientes pela erradicação de Gramnegativos isolados até CIM $4 \mathrm{mg} / \mathrm{L}$ como registrado na Figura 8. Registrou-se cura de um paciente após infusão intermitente piperacilina, e de quatro pacientes após infusão estendida.

Por outro lado, a cura das infecções contra EB e NEB CIM 2mg/L pelo carbapenêmico ocorreu para 10 pacientes que receberam a infusão intermitente de meropenem; enquanto que oito pacientes que receberam a infusão estendida evidenciaram cobertura contra Gramnegativos até CIM $4 \mathrm{mg} / \mathrm{L}$.

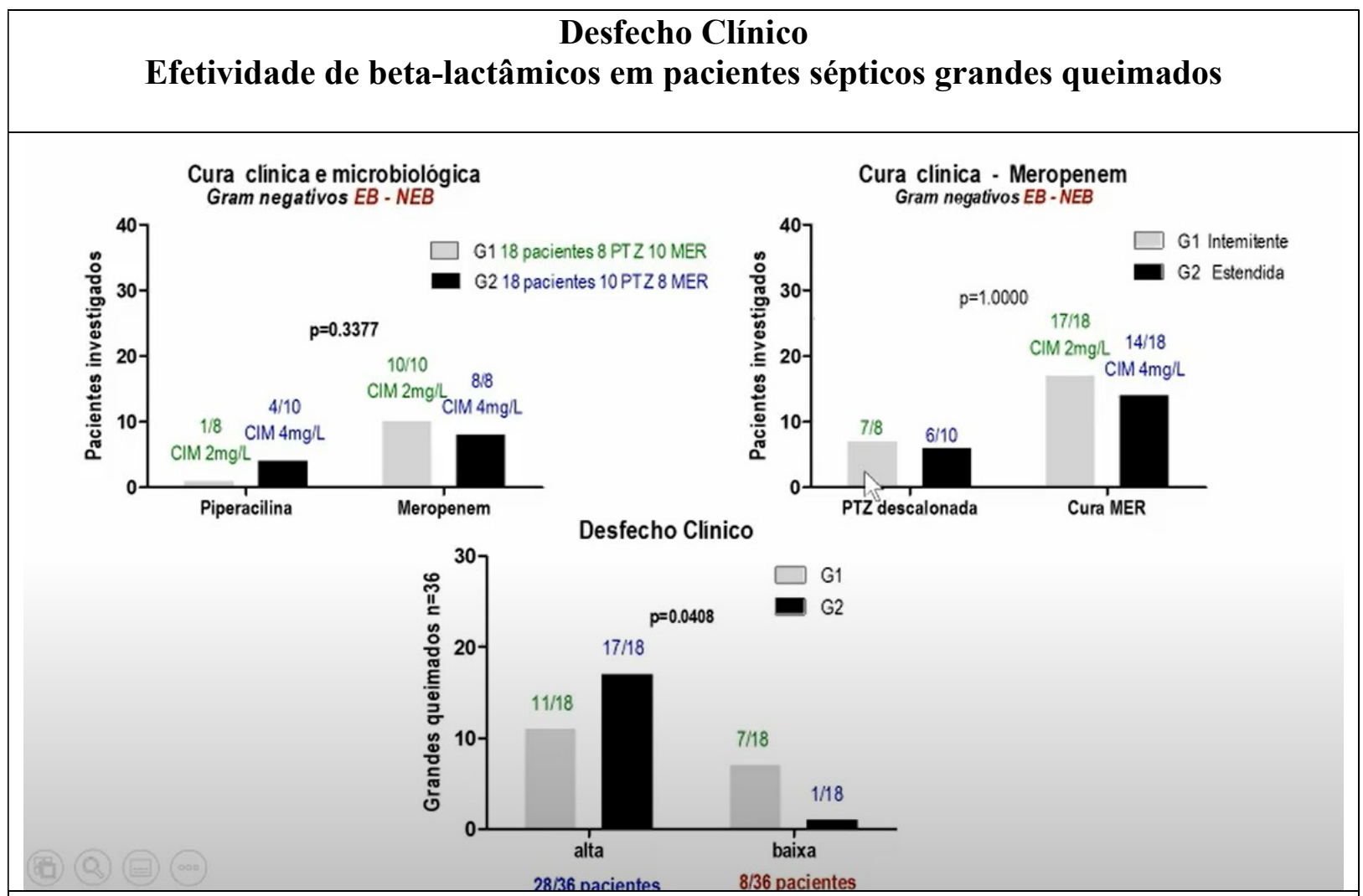

Figura 8 - Estudo de desfecho clínico para 36 pacientes sépticos grandes queimados recebendo terapia com beta- lactâmicos após infusão de $0,5 \mathrm{~h} / \mathrm{G} 1$ versus $3 \mathrm{~h} / \mathrm{G} 2$ na fase precoce do primeiro choque séptico

Então, o meropenem após infusão intermitente promoveu a cura clínica de 17/18 pacientes do Grupo 1, contra os isolados de até CIM $2 \mathrm{mg} / \mathrm{L}$; enquanto que a cura clínica ocorreu para 14/18 pacientes do Grupo 2 após administração da infusão estendida do meropenem que garantiu a cobertura de patógenos de sensibilidade intermediária até CIM de $4 \mathrm{mg} / \mathrm{L}$. Finalmente, registraram-se 25 altas e 11 baixas hospitalares durante o período da internação hospitalar de 36 pacientes grandes queimados. 


\section{DISCUSSÃO}

Sabe-se que até o momento, o monitoramento sérico de agentes beta-lactâmicos é pouco frequente nos hospitais terciários, incluindo os de países do primeiro mundo, uma vez que a dosagem sérica desses antimicrobianos não é realizada de rotina nos pacientes em terapia intensiva. Assim sendo, a individualização da dose e o melhor tipo de infusão ainda permanecem em discussão na terapia de pacientes sépticos. Nesse contexto, atualmente a conduta clínica se baseia na coleta de culturas e na prescrição empírica destes antimicrobianos na dose recomendada no onset do choque séptico considerando-se ainda a função renal de cada paciente. Tal fato justifica a realização da dosagem sérica no suporte laboratorial fornecido em tempo real para os antimicrobianos de administração sistêmica que são prescritos no tratamento das infecções causadas por patógenos hospitalares. Então, a dosagem sérica desses antimicrobianos, seguida da investigação da farmacocinética, e a estimativa do índice de predição de efetividade pela abordagem $\mathrm{PK} / \mathrm{PD}$ se faz imprescindível à equipe médica para individualização da terapia, atingindo consequentemente desfecho clínico desejado. Ressalta-se ainda que tal medida simples, se implantada na rotina de laboratório central do hospital, evitaria o desenvolvimento de cepas mutantes, principalmente para a $K$. pneumoniae e $P$. aeruginosa, consequência da subterapia que ocorre durante a síndrome da resposta inflamatória sistêmica (SRIS) na fase precoce do choque séptico.

A farmacocinética de antimicrobianos hidrofílicos com meropenem ou piperacilina está alterada na fase precoce do choque séptico. Sugere-se ainda que diferentes alterações ocorram após a infusão seja intermitente $(0,5$ h), e após a infusão estendida; trabalhos recentes reportam que estas alterações impactam a cobertura destes antimicrobianos na fase precoce do choque séptico.

Com relação ao alvo a ser atingido pela terapia com esses agentes, sabe-se que a efetividade destes antimicrobianos é tempo-dependente. No caso da piperacilina/tazobactam, o índice de efetividade de $70 \% f \Delta \mathrm{T}>\mathrm{CIM}$ foi inicialmente recomendado contra patógenos Gram-negativos de alta prevalência nos isolados de pacientes em terapia intensiva (KAYS et al., 1999). No caso do meropenem, agente carbapenêmico com alta penetração no tecido pulmonar e nos tecidos moles, destaca-se que o alvo inicialmente recomendado foi de $40 \%$ $f \Delta \mathrm{T}>\mathrm{CIM}$, mas novos protocolos foram realizados posteriormente utilizando alvos superiores (IKAWA et al., 2008). 
Dois estudos do meropenem relativamente recentes que foram conduzidos nos pacientes sépticos em terapia intensiva compararam a infusão intermitente, $0,5 \mathrm{~h}$ com a infusão estendida, utilizando diferentes alvos $\mathrm{PK} / \mathrm{PD}, 60 \% f \Delta \mathrm{T}>\mathrm{MIC}$ e $100 \% f \Delta \mathrm{T}>\mathrm{MIC}$ (ABDULL AZIZ et al., 2015; SILVA JUNIOR et al., 2017a). No protocolo conduzido por Silva Junior (2017a), 20 pacientes sépticos receberam o regime $1 \mathrm{~g}$ q8h, após infusão intermitente de $0,5 \mathrm{~h}$ em 10 pacientes e após infusão estendida de 3 horas no restante. Isolaram-se patógenos gram-negativos sensíveis ao antimicrobiano com destaque para $K$. pneumoniae, Enterobacter cloacae, Pseudomonas aeruginosa dos sítios de infecção da corrente sanguínea, pneumonia não relacionada a ventilação mecânica, infecção de ferida e de osso. Todos os pacientes evidenciaram cobertura contra patógenos Gram- negativos até CIM $2 \mathrm{mg} / \mathrm{L}$, independentemente da infusão; enquanto que se registrou a erradicação do isolado de $P$. aeruginosa de sensibilidade intermediária CIM 4mg/L para 1/10 após a infusão estendida. Destaca-se ainda neste estudo que o alvo PK/PD de 60\% $f \Delta \mathrm{T}>\mathrm{CIM}$ foi considerado pelos autores ao invés do inicialmente recomendado 40\% $f \Delta \mathrm{T}>\mathrm{CIM}$ (IKAWA et al., 2008; SILVA JUNIOR et al., 2017a).

Num outro estudo em 15 pacientes sépticos internados na UTI conduzido por Gonçalves-Pereira (2014) em hospital de Lisboa, Portugal. Todos os pacientes receberam meropenem no regime de dose, $1 \mathrm{~g}$ q $8 \mathrm{~h}$, pela infusão intermitente de $0,5 \mathrm{~h}$ no tratamento de infecções da corrente sanguínea, pulmão, sistema nervoso central, pele/tecidos moles, e infecção complicada pós-cirurgia intra-abdominal. A abordagem PK/PD evidenciou que o alvo de $100 \% f \Delta \mathrm{T}>\mathrm{MIC}$, considerado foi atingido para 14/15 pacientes até CIM $2 \mathrm{mg} / \mathrm{L}$, reduzindo-se para 9/15 pacientes contra patógenos de sensibilidade intermediária, CIM 4mg/L (GONÇALVES PEREIRA et al., 2014).

Destaca-se que alvos diferentes foram considerados nestes dois estudos para a medida da efetividade do meropenem através da abordagem PK/PD.

Como nas últimas duas décadas, Abdull-Aziz (2016) reportou a seleção de mutantes que ocorreu pela erradicação de cepas sensíveis (CIM 0,25-2 mg/L) para $K$. pneumoniae, $P$. aeruginosa, Gram-negativos de alta prevalência na maioria das UTIs, então, diversos protocolos controlados foram conduzidos em pacientes críticos em terapia com o meropenem utilizando estratégias relacionadas à duração da infusão $(1 \mathrm{~h}, 2 \mathrm{~h}, 3 \mathrm{~h})$, ao invés de 0,5 h recomendada em bula, e ao alvo a ser atingido para cobertura do meropenem contra cepas de sensibilidade intermediária de Gram-negativos, CIM 4-8 mg/L (ABDULL-AZIZ et al., 2016). 
Investigou-se ainda o impacto na cobertura do antimicrobiano, além de se testarem novos alvos para atingir o desfecho clínico desejado de 50\% 60\% até $100 \% f \Delta \mathrm{T}>\mathrm{CIM}$, em substituição a $40 \% f \Delta \mathrm{T}>\mathrm{CIM}$, inicialmente recomendado para agentes carbapenêmicos de administração sistêmica (IKAWA et al., 2008).

Mais recentemente, investigou-se através de estudos prospectivos, o aumento da cobertura resultante da infusão estendida de 3 horas para o meropenem com base nos novos índices de efetividade testados nos pacientes sépticos com função renal preservada. A revisão dos demais estudos relativos à farmacocinética, consideraram os alvos de 40 a $50 \% f \Delta \mathrm{T}>\mathrm{CIM}$ para a cobertura deste antimicrobiano após infusão intermitente versus a estendida, descreve os resultados obtidos a partir da realização de estudos controlados conduzidos em pacientes críticos (KOTHEKAR et al., 2020; MATTIOLI et al., 2016; DE WAELE et al., 2014).

Cumpre ressaltar que todas as alterações na farmacocinética registradas para o meropenem nos pacientes sépticos críticos foram comparadas aos dados de referência reportados em voluntários sadios, mesmo regime de dose e tipo de infusão, para se investigar as alterações que ocorrem nos pacientes críticos durante o choque séptico (JARURATANASIRUKUL et al., 2003).

Resumindo, encontramos uma concordância dos nossos resultados comparados aos dados da literatura relativos à alteração da farmacocinética que ocorreu em diferente proporção nos pacientes críticos com função renal preservada, após a infusão intermitente versus a infusão estendida. Ressalta-se ainda que após a infusão estendida de $3 \mathrm{~h}$ para o meropenem, o aumento no volume aparente de distribuição registrado durante a SRIS, teve como consequência, o prolongamento proporcional na meia vida biológica, principalmente no período precoce do choque séptico. Com relação à cobertura do meropenem baseada no alvo de $100 \% f \Delta \mathrm{T}>\mathrm{CIM}$ contra os isolados até CIM 4-8 $\mathrm{mg} / \mathrm{L}$, evidenciou-se a superioridade da infusão estendida comparada a infusão intermitente, para o meropenem pelo alvo atingido na maioria dos trabalhos aqui reportados.

Investigou-se também a alteração da farmacocinética da piperacilina obtida neste estudo comparada a registrada nos diferentes estudos, frente aos valores de referência obtidos por Occhipinti (1997) realizado em voluntários sadios após do regime de dose da combinação piperacilina-tazobactana 4,5 g q8h (OCCHIPINTI et al., 1997). Então, a evidência da alteração na farmacocinética, nos estudos clínicos considerados foi relacionada à maior ou 
menor cobertura do antimicrobiano contra patógenos Gram-positivos e Gram-negativos sensíveis em função do tempo de infusão e ao alvo PK/PD considerado.

Silva Junior (2017b) reportou que 35 pacientes sépticos receberam a infusão intermitente em dois regimes, sendo que 26 pacientes receberam o regime convencional de $4,5 \mathrm{~g}$ q8h, e outros 9 pacientes receberam o regime de 4,5 g q6h. Neste estudo, o alvo de $70 \%$ $f \Delta \mathrm{T}>\mathrm{CIM}$ recomendado por Kays (1999) foi utilizado. Após infusão intermitente $0,5 \mathrm{~h}$ da piperacilina, o regime de $12 \mathrm{~g}$ diários do ativo evidenciou cobertura do antimicrobiano em todos pacientes (26/26) contra patógenos até CIM $2 \mathrm{mg} / \mathrm{L}$, caindo para 23/26 pacientes contra Gram-negativos incluindo-se a P. aeruginosa (CIM 4mg/L). Em contrapartida, considerandose patógenos de sensibilidade intermediária (CIM: 8mg/L), o alvo foi atingido em 1/22 pacientes. O estudo microbiológico revelou culturas para diversos isolados de Gram-positivos com alta incidência de $S$ aureus; Enterobacteriaceae CIM até $2 \mathrm{mg} / L$, e a $P$. aeruginosa CIM 2-4 mg/L foram os Gram-negativos de maior prevalência nas infecções destes pacientes na UTI. Adicionalmente, quando o regime de 4,5g q6h, eq. $16 \mathrm{~g}$ diários foi utilizado, a superioridade de cura clínica e microbiológica ocorreu para todos os pacientes (9/9) investigados frente a dose de $12 \mathrm{~g}$ diários, ambas administradas pela infusão intermitente de 0,5h, uma vez que patógenos com CIM 8-16mg/L foram isolados apenas de 2/9 pacientes (KAYS et al., 1999; SILVA JUNIOR et al., 2017b).

Em função da seleção de mutantes reportada anteriormente no último consenso da Surviving Sepse Campaign relacionada à K. pneumoniae, $P$. aeruginosa e A. baumannii, pela alta incidência e prevalência nas UTIs (RHODES, 2017), diversos protocolos foram conduzidos em pacientes críticos em terapia com a piperacilina-tazobactana utilizando estratégias relacionadas à duração da infusão $(2,3$ e $4 \mathrm{~h})$, ao invés de $0,5 \mathrm{~h}$ recomendada em bula, para avaliação do alvo PK/PD atingido para a cobertura do antimicrobiano contra cepas de sensibilidade intermediária de Gram-negativos, CIM 8-16 mg/L. Investigou-se ainda o impacto na cobertura do antimicrobiano, além de se testarem novos alvos para atingir o desfecho clínico desejado de 50\%, 90\% e 100\% $f \Delta \mathrm{T}>\mathrm{CIM}$, ao invés de $70 \% f \Delta \mathrm{T}>\mathrm{CIM}$, inicialmente recomendado por Kays (1999) para beta-lactâmicos de uso hospitalar contra Gram-negativos (KAYS et al., 1999).

Recentemente, investigou-se através de estudo prospectivo controlado, o aumento da cobertura resultante da infusão estendida de $3 \mathrm{~h}$ para a piperacilina com base nos novos índices de efetividade testados nos pacientes sépticos com função renal preservada. 
Demonstrou-se então, através de estudo a superioridade da cobertura para este tipo de infusão no protocolo conduzido por De Souza (2019) em estudo controlado de dois braços envolvendo 18 pacientes críticos grandes queimados recebendo o regime $4,5 \mathrm{~g}$ q6h por infusão estendida de 2 versus 3h; o alvo PK/PD considerado pelos autores foi de $100 \% f \Delta \mathrm{T}>\mathrm{CIM}$. Registrou-se evidente melhoria no desfecho clínico pela utilização da infusão estendida de $3 \mathrm{~h}$ nos pacientes, uma vez que a cobertura foi garantida até CIM $16 \mathrm{mg} / \mathrm{L}$ para todos os pacientes após a infusão estendida de 3 horas. Em contrapartida, os autores reportam que a efetividade alcançada para a mesma dose pela infusão estendida de 2 horas ocorreu até CIM 4mg/L, com redução da cobertura para isolados de sensibilidade intermediária, CIM $8 \mathrm{mg} / \mathrm{L}$ (7/9) e CIM $16 \mathrm{mg} / \mathrm{L}$ (1/9) pacientes (DE SOUZA et al., 2019).

Sime (2015) em protocolo de controlado incluindo 16 pacientes sépticos com neutropenia febril, e função renal preservada. Realizaram-se apenas duas coletas de amostras sanguíneas. A depuração total corporal se mostrou reduzida, mas o volume de distribuição e a meia vida biológica não foram estimados pelos autores. Registrou-se cobertura do antimicrobiano contra patógenos CIM $16 \mathrm{mg} / \mathrm{L}$ em 11/16 pacientes, consideraram-se na cobertura os isolados de Staphylococcus spp. e de Enterobacteriaceae nestes pacientes O desfecho clínico foi atingido, pela cura clínica e microbiológica de 11/16 pacientes após a infusão estendida de $3 \mathrm{~h}$, empregando o alvo de $100 \% f \Delta \mathrm{T}>\mathrm{CIM}$ considerado pelos autores (SIME et al., 2015).

Chung (2015) descreveu estudo conduzido em 11 pacientes sépticos adultos, função renal preservada. O impacto das alterações da farmacocinética sobre a cobertura do antimicrobiano, após a dose de 4,5g q8h e infusão estendida de 4h, foram registradas. Os autores descreveram pronunciado aumento do volume aparente de distribuição e prolongamento da meia vida biológica garantindo cobertura do antimicrobiano contra isolados incluindo P. aeruginosa e Enterobacteriaceae até CIM $16 \mathrm{mg} / \mathrm{L}$, durante a terapia do choque séptico para todos pacientes para o alvo de $90 \% f \Delta \mathrm{T}>\mathrm{CIM}$, considerado. Da mesma forma De Waale (2014) investigou 15 pacientes sépticos que receberam 4,5g q6h, infusão de 3 horas e pneumonia como sítio de infecção; para o alvo PK/PD de $100 \% f \Delta \mathrm{T}>\mathrm{CIM}$ considerado pelos autores. Neste protocolo evidencio-se aumento do volume de distribuição em 2 a 3 vezes apesar da meia vida permanecer inalterada (CHUNG et al, 2015).

Por outro lado, no estudo de De Waele (2014) a depuração total corporal ou clearance da piperacilina variou entre 10 e $23 \mathrm{~L} / \mathrm{h}$, tal resultado para o $\mathrm{CL}_{\mathrm{T}} 23 \mathrm{~L} / \mathrm{h}$, pode ser justificado 
pelo uso de altas doses de vasopressores em alguns pacientes na fase precoce da SIRS, enquanto que valores de $\mathrm{CL}_{\mathrm{T}} 10 \mathrm{~L} / \mathrm{h}$ e meia vida de $0,8 \mathrm{~h}$ estariam relacionados ao término do tratamento do choque séptico nos demais pacientes (DE WAELE et al, 2014).

Com base nos dados obtidos no presente estudo comparados aos resultados reportados na literatura, torna-se relevante considerar que o paciente séptico com função renal preservada, recebe vasopressores principalmente na fase precoce do choque séptico, e evidencia profundas alterações na farmacocinética do antimicrobiano administrado por infusão estendida, impactando positivamente a cobertura da piperacilina, infusão $3 \mathrm{~h}$, na fase mais crítica da infecção nosocomial, uma vez que a cobertura foi garantida para isolados até CIM $16 \mathrm{mg} / \mathrm{L}$. Entretanto, larga variabilidade de resultados na depuração total corporal da piperacilina podem ocorrer quer pelo uso de vasopressores em doses tituladas de acordo com a necessidade maior ou menor de cada paciente com relação bem como ao uso de altas doses de vasopressores em alguns pacientes sépticos incluídos no presente protocolo, e outros pacientes do estudo de De Waele (2014).

Considerando-se os alvos PK/PD até $100 \% f \Delta \mathrm{T}>\mathrm{CIM}$ na cobertura deste antimicrobiano após infusão estendida, sugere-se que o tempo de infusão de 3 horas para o meropenem $1 \mathrm{~g}$ q $8 \mathrm{~h}$, e para a piperacilina $4 \mathrm{~g}$ q6h nas doses recomendadas no presente protocolo de estudo deva ser utilizado pela superioridade para atingir o alvo terapêutico. A erradicação de patógenos sensíveis, CIM até $2 \mathrm{mg} / \mathrm{L}$, estendida à erradicação de prováveis mutantes, pelos níveis séricos bactericidas no vale contribuem para o desfecho clínico desejado nestes pacientes críticos em terapia intensiva do choque séptico pelos dois betalactâmicos. 


\section{CONCLUSÃO}

Evidenciou-se a superioridade da infusão estendida de 3 horas comparada à infusão intermitente de 0,5 hora na efetividade da piperacilina e do meropenem administrados nas doses recomendadas para o alvo terapêutico $100 \% f \Delta \mathrm{T}>\mathrm{CIM}$ considerado.

$\mathrm{O}$ aumento na cobertura contra patógenos Gram-negativos pode ser justificado pelas alterações que ocorreram na farmacocinética dos antimicrobianos nos dois grupos de pacientes grandes queimados sépticos frente aos dados reportados para voluntários sadios.

Além disso, foi registrada diferença significativa entre os grupos de pacientes que receberam infusão intermitente após comparação com aqueles pacientes que receberam infusão estendida de cada antimicrobiano considerado. Desta forma, tais resultados justificam a superioridade da infusão estendida obtida tanto para a piperacilina como para o meropenem nos pacientes sépticos grandes queimados. 


\section{REFERÊNCIAS}

1 ABDUL-AZIZ, M. H. et al. Is prolonged infusion of piperacillin/tazobactam and meropenem in critically ill patients associated with improved pharmacokinetic/pharmacodynamic and patient outcomes? An observation from the Defining Antibiotic Levels in Intensive care unit patients (DA. Journal of Antimicrobial Chemotherapy, v. 71, n. 1, p. 196-207, 2016. Disponível em: $<$ https://doi.org/10.1093/jac/dkv288>. Acesso em 18 nov. 2020.

2 AGÊNCIA NACIONAL DE VIGILÂNCIA SANITÁRIA (ANVISA). Diretriz Nacional para Elaboração de Programa de Gerenciamento do Uso de Antimicrobianos em Serviços de Saúde. 2017. Disponível: $<$ http://portal.anvisa.gov.br/documents/33852/271855/Diretriz+Nacional+para+Elabora\%C3\%A7\%C3\%A $30+d e+$ Programa + de + Gerenciamento + do + Uso + de + Antimicrobianos + em + Servi $\% \mathrm{C} 3 \% \mathrm{~A} 7 \mathrm{os}+\mathrm{de}+\mathrm{Sa} \% \mathrm{C} 3 \%$ BAde/667979c2-7edc-411b-a7e0-49a6448880d4>. Acesso em 17 nov. 2020.

3 BAQUERO, F.; MARTINEZ, J.L; CANTON, R. Antibiotics and antibiotic resistance in water environments. Currente Opinion in Biotechnology. 2008; 19:260-265. Disponível em: $<$ https://doi.org/10.1016/j.copbio.2008.05.006>. Acesso em 18 nov. 2020.

4 BHARWANA, S.; FARID, M.; ALI, S.; RIZWAN, M.; NADEEM, M.; HAIDER, M.; TAUQEER, H.; SALLAH-UD-DIN, R.; AHMAD, R. Mortality rate associated with hospital acquired infections among burn patients. Biomedical Research and Therapy. v. 3, n. 9, p. 790-799, 2016. Disponível em: <http://www.bmrat.org/index.php/BMRAT/article/view/2>. Acesso em 06 nov. 2020.

5 BITTNER, E.A.; SHANK, E.; WOODSON, L.; MARTYN, J.A. Acute and perioperative care of the burninjured patient. Anesthesiology. v. 122, n. 2, p. 448 - 464. Disponível em: $<$ https://www.ncbi.nlm.nih.gov/pmc/articles/PMC4844008/pdf/nihms643790.pdf>. Acesso em 06 nov. 2020. https://doi.org/10.1097/ALN.0000000000000559. PMID: 25485468; PMCID: PMC4844008

6 BLANCHET, B.; JULLIEN, V.; VINSONNEAU, C.; TOD, C. Influence of burns on pharmacokinetics and pharmacodynamics of drugs used in the care of burn patients. Clinical Pharmacokinetics, v. 47, n. 10, p. 635-654, 2008. Disponível em: <https://doi.org/10.2165/00003088-200847100-00002>. Acesso em 16 nov. 2020.

7 BLUMER, J. L. Meropenem: Evaluation of a new generation carbapenem. International Journal of Antimicrobial Agents. $\quad$ v. 8, n. 2, p. $13-92 . \quad$ Disponível em: $<$ https://www.sciencedirect.com/science/article/pii/S0924857996003470>. Acesso em 04 jun. 2020. https://doi.org/10.1016/S0924-8579(96)00347-0

8 CHOW, C.; KUMARASINGHE, G.; LIEW, H. Y. Antimicrobial resistance: Patterns and trends in the National University Hospital, Singapore ( 1989-1991 ). Malays J Pathol. v. 14, n. 2, p. 95-103, 1992. Disponível em: <https://pubmed.ncbi.nlm.nih.gov/1304631/>. Acesso em 02 nov. 2020. PMID: 1304631.

9 CHURCH, D.; ELSAYED, S.; REID, O.; WINSTON, B.; LINDSAY, R. (2006, April). Burn wound infections. Clinical Microbiology Reviews. v. 19, n. 2, p. 403 - 434, 2006. Disponível em: $<$ https://www.ncbi.nlm.nih.gov/pmc/articles/PMC1471990/pdf/0023-05.pdf >. Acesso em 10 nov. 2020. https://doi.org/10.1128/CMR.19.2.403-434.2006. PMID: 16614255; PMCID: PMC1471990.

10 COCKCROFT, D. W.; GAULT, M. H. Prediction of creatinine clearance from serum creatinine. Nephron, v. 16, n. 1, p. 31-41, 1976. Disponível em: <https://doi.org/10.1159/000180580>. Acesso em 01 nov. 2020.

11 COMISSÃO DE CONTROLE DE INFECÇÕES HOSPITALARES DO HOSPITAL DAS CLÍNICAS DA UNIVERSIDADE DE SÃO PAULO (CCIH-FMUSP). Guia de utilização de anti-infecciosos e recomendações para a prevenção de infecções hospitalares. 5ed. São Paulo: Hospital das Clínicas, 2018-20.

12 DE WAELE, Jan J. et al. Therapeutic Drug Monitoring-Based Dose Optimisation of Piperacillin and Meropenem: A Randomised Controlled Trial. Intensive Care Medicine, v. 40, n. 3, p. 380-387, 20 dez. 2014. Disponível em: <http://dx.doi.org/10.1007/s00134-013-3187-2>. Acesso em 25 nov. 2020.

13 DIPIRO, J. T.; SPRUILL, W. J.; WADE, W. E.; BLOUIN, R. A.; PRUEMER, J. M.; Concepts in clinical pharmacokinetics. 5 ed. Bathesda. American Society of Health-System Pharmacists, 2010.

14 DRUSANO, G. Meropenem: Laboratory and clinical data. Clinical Microbiology and Infection, v. 3, n. suppl 4, p. 4S51-4S59, 1997. Disponível em: <https://doi.org/10.1016/s1198-743x(14)65034-5>. Acesso em 16 nov. 2020. 
15 FRANCK, C. L.; RIBAS-FILHO, J. M.; SENEGAGLIA, A. C.; GRAF, R. M.; LEITE, L. M. B. A complexidade cicatricial em queimaduras e a possibilidade da terapia com células-tronco derivadas do tecido adiposo : revisão. Revista Brasileira de Queimaduras, v. 16, n. 2, p. 111-116, 2017. Disponível em: <http://www.rbqueimaduras.com.br/details/372/pt-BR/a-complexidade-cicatricial-em-queimaduras-ea-possibilidade-da-terapia-com-celulas-tronco-derivadas-do-tecido-adiposo--revisao $>$

16 FU, K. P.; NEU, H. C. Piperacillin , a New Pencillin Active Against Many Bacteria Resistant to Other Penicillins. Antimicrobial Agents and Chemotherapy. v. 13, n. 3, 1978. Disponível em: $<$ https://aac.asm.org/content/aac/13/3/358.full.pdf >. Acesso em 01 nov. 2020. doi: 10.1128/aac.13.3.358. PMID: 122519; PMCID: PMC352246.

17 GAIESKI, D.F.; MIKKELSEN, M.E.; BAND, R.A.; PINES, J.M.; MASSONE, R.; FURIA, F.F.; SHOFER, F.S.; GOYAL, M. Impact of time to antibiotics on survival in patients with severe sepsis or septic shock in whom early goal-directed therapy was initiated in the emergency department. Crit Care Med. v. 38, p. 4, p. 1045-1053, 2010. Disponível em: $<$ https://journals.lww.com/ccmjournal/Fulltext/2010/04000/Impact_of_time_to_antibiotics_on_survival_in. 5.aspx>. Acesso em 10 nov. 2020. https://doi.org/10.1097/CCM.0b013e 3181 cc 4824

18 GLOBAL SEPSIS ALLIANCE (GSI). SEPSIS AND COVID-19 / CORONAVIRUS / SARS-COV-2. 2020. Disponível em: $<$ https://www.global-sepsis-alliance.org/covid19>. Acesso 15 junho 2020.

19 HENRIQUE, D.M.; SILVA, L.D.; COSTA, A.C. R.; REZENDE, A.P.M.B.; SANTOS, J.A.S.; MENEZES, M.M.; MAURER, T.C. Controle de infecção no centro de tratamento de queimados: revisão de literatura. Rev Bras Queimaduras. v. 12, n. 4, p. 230-234, 2013. Disponível em: $<\mathrm{http}: / /$ rbqueimaduras.org.br/content/imagebank/pdf/v12n4.pdf $>$. Acesso em 05 nov. 2020.

20 GONÇALVES-PEREIRA, J.; et al. Assessment of pharmacokinetic changes of meropenem during therapy in septic critically ill patients. BMC Pharmacology and Toxicology, v. 15, n. 1, 14 abr. 2014. Disponível em: $<$ http://dx.doi.org/10.1186/2050-6511-15-21>. Acesso em 25 no. 2020.

21 INSTITUTO LATINO AMERICANO DE SEPSE (ILAS). Sepse: Um problema de saúde pública. Brasília: 2015. Disponível em: <https://ilas.org.br/assets/arquivos/upload/Livro-ILAS(Sepse-CFM-ILAS).pdf>. Acesso em 17 nov. 2020.

22 INSTITUTO LATINO AMERICANO DE SEPSE. Programa de Melhoria de Qualidade Protocolos Gerenciados de Sepse: Relatório Nacional Ano de Referência 2019. São Paulo, 2019. Disponível em: $<$ https://www.ilas.org.br/dados-brasileiros.php>. Acesso em 17 nov. 2020.

23 JARURATANASIRIKUL, S.; SRIWIRIYAJAN, S. Comparison of the pharmacodynamics of meropenem in healthy volunteers following administration by intermittent infusion or bolus injection. Journal of Antimicrobial Chemotherapy, v. 52, n. 3, p. 518-521, 2003. DOI: 10.1093/jac/dkg378. Acesso em 01 nov. 2020.

24 JONES, R. N.; BARRY, A. L. Studies to Optimize the In Vitro Testing of Piperacillin Combined with Tazobactam ( YTR 830 ). DIAGN MICROBIOL INFECT DIS. v.12, n. 6, p. 495-510, 1989. Disponível em: <http://www.sciencedirect.com/science/article/pii/0732889389900849>. Acesso em 03 nov. 2020. https://doi.org/10.1016/0732-8893(89)90084-9

25 KAYS, M. B. Comparison of five $\beta$-lactam antibiotics against common nosocomial pathogens using the time above MIC at different creatinine clearances. Pharmacotherapy, v. 19, n. 12, p. 1392-1399, 1999. Disponível em: < https://doi.org/10.1592/phco.19.18.1392.30900>. Acesso em 21 nov. 2020.

26 KIM, M.K.; CAPITANO, B.; MATTOES, H.M.; XUAN, D.; QUINTILIANI, R.; NIGHTINGALE, C.H.; NICOLAU, D.P. Pharmacokinetic and pharmacodynamic evaluation of two dosing regimens for piperacillin-tazobactam. Pharmacotherapy, v. 22, n. 5, p. 569-577, 2002. Disponível em: $<$ https://doi.org/10.1592/phco.22.8.569.33209>. Acesso em 16 nov. 2020.

27 KOTHEKAR, A. T., DIVATIA, J. V., MYATRA, S. N., PATIL, A., NOOKALA KRISHNAMURTHY, M., MAHESHWARAPPA, H. M., SIDDIQUI, S. S., GURJAR, M., BISWAS, S., \& GOTA, V. Clinical pharmacokinetics of 3-h extended infusion of meropenem in adult patients with severe sepsis and septic shock: implications for empirical therapy against Gram-negative bacteria. Annals of intensive care, v. 10, n. 1, p. 4. Disponível em <https://doi.org/10.1186/s13613-019-0622-8>. Acesso em 25 nov. 2020. 
28 KUCK, N.A.; JACOBUS, N.V.; PETERSEN, P.J.; WEISS, W.J.; TESTA, R.T. Comparative in vitro and in vivo activities of piperacillin combined with the $\beta$-lactamase inhibitors tazobactam, clavulanic acid, and sulbactam. Antimicrobial Agents and Chemotherapy, v. 33, n. 11, p. 1964-1969, 1989. Disponível em: $<$ https://doi.org/10.1128/aac.33.11.1964>. Acesso em 17 nov. 2020.

29 LACERDA, L.A.; CARNEIRO, A.C.; OLOIVEIRA, A.F.; GRAGMANI, F. L. Estudo epidemiológico da Unidade de Tratamento de Queimaduras da Universidade Federal de São Paulo. Revista Brasileira de Queimaduras. v. 9, n. 3, p. 82-88, 2010. Disponível em: $<$ http://www.rbqueimaduras.com.br/details/40/pt$\mathrm{BR} /$ studo-epidemiologico-da-unidade-de-tratamento-de-queimaduras-da-universidade-federal-de-saopaulo>. Acesso em 06 nov. 2020.

30 LEROY, A.; FILLASTRE, J. P.; BORSA-LEBAS, F.; ETIENNE, I.; HUMBERT, G. Pharmacokinetics of meropenem (ICI 194,660) and its metabolite (ICI 213,689) in healthy subjects and in patients with renal impairment. Antimicrobial Agents and Chemotherapy, v. 36, n. 12, p. 2794-2798, 1992. Disponível em: $<$ https://doi.org/10.1128/AAC.36.12.2794>. Acesso em 16 nov. 20020.

31 MALTA, D.C.; BERNAL, R.T.I.; LIMA, C.M.; CARDOSO, L.S.M.; ANDRADE, F.M.D.; MARCATTO, J.O.; GAWRYSZEWSKI, V.P. Perfil dos casos de queimadura atendidos em serviços hospitalares de urgência e emergência nas capitais brasileiras em 2017. Revista Brasileira de Epidemiologia. v. 23, supl. 1, e200005.SUPL.1, 2020. Disponível em: $<$ https://www.scielo.br/scielo.php?script=sci_arttext\&pid=S1415-790X2020000200403\&tlng=pt $>$. Acesso em 05 nov. 2020. https://doi.org/10.1590/1980-549720200005.supl.1.

32 MATTIOLI, F.; et al. Population Pharmacokinetics and Probability of Target Attainment of Meropenem in Critically Ill Patients. European Journal of Clinical Pharmacology, v. 72, n. 7, p. 839-848, 6 abr. 2016. Disponível em: <http://dx.doi.org/10.1007/s00228-016-2053-x>. Acesso em 25 nov. 2020.

33 Meropenem (meronem, zeneca). Intensive \& critical care nursing. v. 11, n. 5, p. 298-299, 1995. Disponível em: <https://www.sciencedirect.com/science/article/pii/S0964339795818332?via\%3Dihub>. Acesso em 04 jun. 2020. https://doi.org/10.1016/S0964-3397(95)81833-2. PMID: 7492890.

34 MINISTÉRIO DA SAÚDE (BRASIL). Biblioteca Virtual em Saúde: Queimaduras. Brasil, 2015. Disponível em: <https://bvsms.saude.gov.br/dicas-em-saude/2109-queimaduras $>$. Acesso em 21 nov.2020.

35 CHOW, C.; KUMARASINGHE, G.; LIEW, H. Y. Antimicrobial resistance: Patterns and trends in the National University Hospital, Singapore ( 1989-1991 ). Malays J Pathol. v. 14, n. 2, p. 95-103, 1992. Disponível em: <https://pubmed.ncbi.nlm.nih.gov/1304631/>. Acesso em 02 nov. 2020. PMID: 1304631.

36 NATIONAL CENTER FOR BIOTECHNOLOGY INFORMATION. "PubChem Compound Summary for CID 441130, Meropenem" PubChem. Disponível em: $<$ https://pubchem.ncbi.nlm.nih.gov/compound/Meropenem>. Acesso em 04 dez. 2020.

37 NATIONAL CENTER FOR BIOTECHNOLOGY INFORMATION. PubChem Database. Piperacillin sodium, CID=23666879. Disponível em: <https://pubchem.ncbi.nlm.nih.gov/compound/Piperacillinsodium>. Acesso em 04 dez. 2020.

38 NATIONAL CENTER FOR BIOTECHNOLOGY INFORMATION. PubChem Database. Tazobactam sodium, $\mathrm{CID}=23663400$. Disponível em: <https://pubchem.ncbi.nlm.nih.gov/compound/Tazobactamsodium>. Acesso em 04 dez. 2020.

39 NORBURY, W.; HERNDON, D.N.; TANKSLEY, J.; JESCHKE, M.G.; FINNERTY, C.C. Infection in Burns. Surg Infect (Larchmt). v. 17, n. 2, p. 250-255, 2016. Disponivel em: $<$ https://www.ncbi.nlm.nih.gov/pmc/articles/PMC4790211/>. Acesso em 07 nov. 2020 . doi: 10.1089/sur.2013.134. PMID: 26978531; PMCID: PMC4790211.

40 OCCHIPINTI, D. J.; PENDLAND, S. L.; SCHOONOVER, L. L.; RYPINS, E. B.; DANZIGER, L. H.; RODVOLD, K. A. Pharmacokinetics and Pharmacodynamics of Two Multiple-Dose PiperacillinTazobactam Regimens. Antimicrobial agents and chemotherapy, v. 41, n. 11, p. 2511-2517, 1997. Disponível em: <https://doi.org/10.1128/AAC.41.11.2511>. Acesso em 01 nov. 2020.

41 ORGANIZAÇÃO MUNDIAL DE SAÚDE (OMS). Worldwide country situation analysis: response to antimicrobial resistance, 2015. Disponível em: <https://www.who.int/antimicrobialresistance/publications/situationanalysis/en/>. Acesso em 16 nov. 2020. 
42 ONUFRAK, N. J.; FORREST, A.; GONZALEZ, D. Pharmacokinetic and Pharmacodynamic Principles of Anti-infective Dosing. Clinical Therapeutics, v. 38, n. 9, p. 1930-1947, 2016. Disponível em: $<$ https://www.ncbi.nlm.nih.gov/pmc/articles/PMC5039113/pdf/nihms-800872.pdf $>$. Aceso em 19 nov. 2020. https://doi.org/10.1016/j.clinthera.2016.06.015

43 PAPP-WALlACE, K. M.; ENDIMIANI, A.; TARACILA, M. A.; BONOMO, R. A. Carbapenems: Past, present, and future. Antimicrobial Agents and Chemotherapy, v. 55, n. 11, p. 4943-4960, 2011. Disponível em: <https://doi.org/10.1128/AAC.00296-11>. Acesso em 16 nov. 2020.

44 PATEL, P. R.; COOK, S. E. (1997). Stability of meropenem in intravenous solutions. American Journal of Health-System Pharmacy, v. 54, n. 4, p. 412-421, 1997. Disponível em: $<$ https://doi.org/10.1093/ajhp/54.4.412>. Acesso em 18 nov. 2020.

45 PICCOLO, N.S.; SERRA, M.C.V.F.; LEONARDI, D.F.; LIMA JR, E.M.; NOVAES, F.N.; CORREA, M.D.; CUNHA, L.R.; AMARAL, C.E.R.; PRESTES; M.A.; CUNHA, S.R.; PICCOLO, M.T. Projeto diretrizes - Queimaduras: Diagnóstico e Tratamento Inicial. Sociedade Brasileira de Cirurgia Plástica. 2008. Disponível em: <https://diretrizes.amb.org.br/_BibliotecaAntiga/queimaduras-diagnostico-etratamento-inicial.pdf $>$. Acesso em 05 nov.2020.

46 RHODES, A.; EVANS, L.E.; ALHAZZANI, W.; et al. Surviving Sepsis Campaign: International Guidelines for Management of Sepsis and Septic Shock: 2016. Intensive Care Med. V. 43, n. 3, p. 304377, 2017. Disponível em: < https://link.springer.com/article/10.1007/s00134-017-4683-6>. Acesso em 10 nov. 2020. https://doi.org/10.1007/s00134-017-4683-6

47 ROBERTS, J. A.; LIPMAN, J. Pharmacokinetic issues for antibiotics in the critically ill patient. Critical care medicine. V. 37, n. 3, p. 840-859, 2009. Disponível em: https://doi.org/10.1097/CCM.0b013e3181961bff>. Acesso em 20 nov. 2020.

48 RUDD, K.E. Global, regional, and national sepsis incidence and mortality, 1990-2017: analysis for the Global Burden of Disease Study. Lancet, v. 395, n. 10219, p. 200-211, 2020. Disponível em: $<$ https://www.ncbi.nlm.nih.gov/pmc/articles/PMC6970225/?report=reader>. Acesso em 10 nov. 2020. doi: 10.1016/S0140-6736(19)32989-7. PMID: 31954465; PMCID: PMC6970225.

49 RYBAK, M. J. Pharmacodynamics: Relation to antimicrobial resistance. American Journal of Infection Control, v. 34, n. 5 SUPPL., p. 38-45, 2006. Disponível em: $<$ https://www.sciencedirect.com/science/article/pii/S0196655306008443?via\%3Dihub>. Acesso em 19 nov. 2020. https://doi.org/10.1016/j.ajic.2006.05.227

50 SANCHES, C.; CAMPOS, E.V.; GOMEZ, D.S.; FERREIRA, M.C.; SILVA JR, C. V.; SANTOS, A. M.; SANTOS, S.R.C.J. Therapeutic Drug Monitoring of Antimicrobials for Dose Adjustment in Patients from the Intensive Care Burn Unit. In: International Conference on Antimicrobial Research/ICAR-2010, 2010, Valladolid, Spain. I International Conference on Antimicrobial Research - ICAR2010. Baldajoz: Formatex, 2010. v. 1. p. 77-78.

51 SANTOS, S.; SANCHES-GIRAUD, C.; DE SOUZA, F.; GÓMEZ, D.; CAMPOS, E.; AZEVEDO, R.; FERREIRA, M.; Pharmacokinetic-pharmacodynamic correlation for meropenem applied to a burn child using a bioanalytical liquid cromatographic method. Revista Portuguesa De Farmacoterapia, v. 3, n. 4, p. 4-12. Disponível em: <https://doi.org/10.25756/rpf.v3i4.79>. Acesso em 03 nov. 2020.

52 SILVA JR, J.M; OLIVEIRA, A.M.R.R; SILVA, C.V; SANTOS, S.R.C.J; GOMEZ, D.S. Piperacillin effectiveness in septic burn patients by comparison of two empiric daily dose 12 versus $16 \mathrm{~g}$ against susceptible strains based on drug plasma measurements done in a real time. BMC Critical Care. 2017; 21(S2): 31-31.

53 SOCIEDADE BRASILEIRA DE QUEIMADURAS. Internações por queimaduras com álcool 70\% sobem no país. 2020. Disponível em: <https://sbqueimaduras.org.br/noticia/internacoes-por-queimaduras-comalcool-70-sobem-no-pais>. Acesso em 06 nov.2020.

54 SOUZA, A.A.; MATTAR, C.A.; ALMEIDA; P.C.C.; FAIWICHOW, L.; FERNANDES, F.S.; NETO; E.C.A.; MANZOTTIMS, P. L. Perfil epidemiológico dos pacientes internados na Unidade de Queimaduras do Hospital do Servidor Público Estadual de São Paulo. Revista Brasileira De Queimaduras. v. 8, n. 3, p. 87-90, 2009. Disponível em: <http://www.rbqueimaduras.com.br/details/18/pt-BR/perfil-epidemiologicodos-pacientes-internados-na-unidade-de-queimaduras-do-hospital-do-servidor-publico-estadual-de-saopaulo>. Acesso em 05 nov. 2020. 
55 SOUZA, V.K.; SILVA JR, E.M..; MATSUNO, V.; SILVA JR, J.M.; GOMIDES, A.S.; OLIVEIRA, T. C.; FERREIRA, G.A.; SANTOS, S.R.C.J. Extended two hours infusion improves piperacillin effectiveness against susceptible strains in septic burn patients. Critical Care, v. 23(Suppl 3):237, p. 20-21, 2019.

56 SUNAGAWA, M.; MATSUMURA, H.; INOUE, T.; FUKASAWA ,M.; KATO, M. A novel carbapenem antibiotic, SM-7338 structure-activity relationships. J Antibiot (Tokyo). V. 43, n. 5, p. 519-532, 1990. Disponível em: <https://www.jstage.jst.go.jp/article/antibiotics1968/43/5/43_5_519/_pdf/-char/en>. Acesso em 03 nov. 2020. https://doi.org/10.7164/antibiotics.43.519. PMID: 2358404

57 SWEET, R.L.; ROBBIE, M.O.; OHM-SMITH, M.; HADLEY, W.K. Comparative study of piperacillin versus cefoxitin in the treatment of obstetric and gynecologic infections. The American Journal of Obstetrics and Gynecology, v. 145, n. 3, p. 342-349, 1983. Disponível em: $<$ http://dx.doi.org/10.1016/0002-9378(83)90722-6>. Acesso em 17 nov. 2020.

58 UDY, A.A.; ROVERTS, J.A.; LIPMAN, J. Clinical implications of antibiotic pharmacokinetic principles in the critically ill. Intensive Care Med. V. 39, p. 2070-2082, 2013. Disponível em: $<$ http://dx.doi.org/10.1007/s00134-013-3088-4>. Acesso em 17 nov. 2020.

59 VAN DUIN, D.; STRASSLE, P.D.; DIBIASE, L.M.; LACHIEWICZ, A.M.; RUTALA, W.A.; EITAS, T.; MAILE, R.; KANAMORI, H.; WEBER, D.J.; CAIRNS, B.A.; NAPRAVNIK, S.; JONES, S.W. Timeline of health care-associated infections and pathogens after burn injuries. Am J Infect Control. v. 44, n. 12, p. 1511-1516, 2016.2 Disponível em: <https://www.ncbi.nlm.nih.gov/pmc/articles/PMC5388443/pdf/nihms822844.pdf>. Acesso em 10 nov.2020. https://doi.org/10.1016/j.ajic.2016.07.027. PMID: 27742146; PMCID: PMC5388443.

60 VERBIST, L. In Vitro Activity of Piperacillin, a New Semisynthetic Penicillin with an Unusually Broad Spectrum of Activity. Antimicrobial Agents Chemotherapy. v. 13, n. 3, p. 349-357, 1978. Disponível em: $<$ https://www.ncbi.nlm.nih.gov/pmc/articles/PMC352245/pdf/aac00285-0007.pdf >. Acesso em 01 nov. 2020. httpps:doi:10.1128/aac.13.3.349.

61 WEINBRER, M.J. Pharmacokinetics of antibiotics in burn patients. Journal of Antimicrobial Chemotherapy. V. 44, n. 3, p. 319-327, 1999. Disponível em <https:// https://doi.org/10.1093/jac/44.3.319>. Acesso em 17 nov. 2020.

62 WISE, R.; LOGAN, M.; COOPER, M.; ANDREWS, J.M. Pharmacokinetics and Tissue Penetration of Tazobactam Administered Alone and with Piperacillin. Antimicrob Agents Chemother. v. 35, n. 6, p. 1081-1084, 1991. Disponível em: <https://www.ncbi.nlm.nih.gov/pmc/articles/PMC284290/pdf/aac003760091.pdf>. Acesso em 03 nov. 2020. https://doi.org/10.1128/aac.35.6.1081. PMID: 1656853; PMCID: PMC284290.

63 WORLD HEALTH ORGANIZATION (WHO). Burns. 2018. Disponível em: $<$ https://www.who.int/en/news-room/fact-sheets/detail/burns $>$. Acesso em 05 nov. 2020.

64 YU, Z.; PANG, X.; WU, X.; SHAN, C.; JIANG, S. Clinical outcomes of prolonged infusion (extended infusion or continuous infusion) versus intermittent bolus of meropenem in severe infection: A metaanalysis. PloS one, v. 13, n. 7, e0201667, 2018. Disponível em: <https://doi.org/10.1371/journal.pone.0201667>. Acesso em 17 nov. 2020. 


\title{
8. APÊNDICE
}

\subsection{Termo de consentimento livre esclarecido (TCLE)}

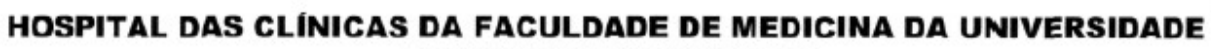
DE SÃO PAULO-HCFMUSP

\author{
TERMO DE CONSENTIMENTO LIVRE E ESCLARECIDO
}

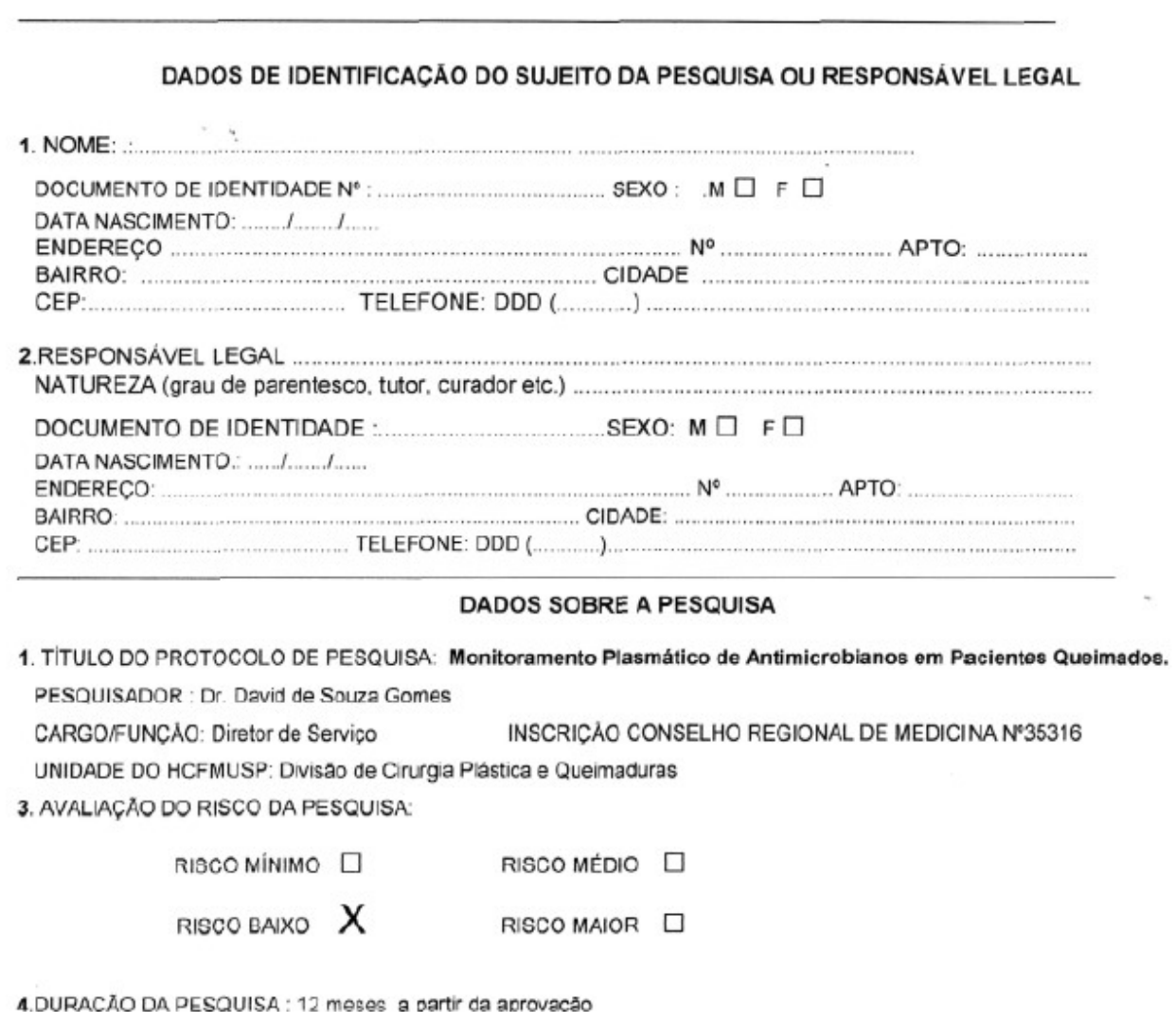




\section{HOSPITAL DAS CLÍNICAS DA FACULDADE DE MEDIGINA DA UNIVERSIDADE}

\section{DE SÃo PAULO-HCFMUSP}

O pesquisador responsável por este protocolo é o Prof. Dr David de Souza Gomes, também participarâo deste estudo o Dr. Edvaldo Vieira, Dra. Cristina Sanches Giraud e Profa Dra Silvia Regina Cavani Jorge Santos

1. Justificativa e os objetivos da pesquisa: Se o(a) senhor(a) ou pessoa por quem o $\mathrm{Sr}$.(a) é responsável

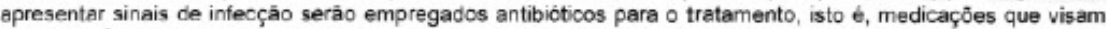
tratar a infecç̃o, consequente da losáo pola qucimadura. Os antibióticos atuaimonte utilizados para esta finalidade sảo anfotercina B caspofungna cefepime, ceftazidima ceftriaxona, ciprofloxacino, fluconazol, iminenem ou mercpenem. linezolida, oxacilina, piperacilinatazobactam, polimixina B ou E e vancomicina. O objetivo do presente estudo é avaliar se um destes antibióticos, na dose e forma utilizadas, atinge quantidades satisfatónias no sangue.

2 Procedimentos que serao utilizados: o senhor ou pessoe por quem o $\mathrm{Sr}$.(a) è responsàvel receberá o antibiótico nas doses o nos momentos normalmente utilizados pelos pacientes com infecçẫo devido a queimaduras. Serảo coletadas no máximo seis amostras de sangue $(1,5-2,0 \mathrm{~mL}$ por coleta) conforme segue: término da infusăo, $2^{2}, 3^{2}, 4^{4}, 6^{a}$ hora $\theta$ imediatamente antes da dose subsequente. Será coletado atraves de cateter venoso (dispositivo que substitui a picada) volume total inferior a $15 \mathrm{~mL}$ de seu sangue para a dosagem cateter venoso (dispositivo que substitui a picada) volume total inferior a $15 \mathrm{~mL}$ de seu sangue para a dosagem
do medicamento. No sangue será dosada a concentraçäo do antibiótico utilizando método laboratorial especifico.

3. Desconforto e ríscos esperados: o risco a que o senhor ou pessoa por quem o $\mathrm{Sr}$. (a) é reeponæsivel serd submetido é mínimo pois o procedimento é feito por profissionais altamente treinados de forma estéril. com todo o material descertavel

4. Beneficios que poderäo ser obtidos: após os resultados de cada avalieção, caso seja necessário, serâo realizados ajustes nas dosos o intervalos de doses de antibioticos utilizados no tratamento. Este estudo devera também futuremente beneficiar muito outros pacientes queimados

5 Procedimentos alternativos que possam ser vantajosos para o indivíduo: neste caso, nấo há procedimentos alternativos, pois se trata de procedimento de escolha e o melhor para pacientes queimados com infecçæo, estes antibioticos, sకొo 06 provistos no protocolo de tratamento de infeç̧ōes com antimicrobianos em grandes queimados

Alórn disto, garantimos que:

1. O Sr. (a) torá acosoo, a qualquer tempo, às informaçổes sobre procedimentos, riscos e beneficios relacionados a pesquisa inclusive esclarecer eventuais dúvidas.

2. Liberdade de retirar seu consentimento a qualquer momento e de deixar de participar do estudo, som quo isto traga projuizo à continuidade da assistência.

3. Tera a confidencialidado, sigilo o privecidade garantidos.

4 Disponibilidade de assistência na DIVISĂO DE CIRURGIA PLASTICA - HCFMUSP, por evontuais danos à saúdo, decorrentes de pesquisa.

5. Direito de ser mantido atualizado sobre os resultados parciais das pesciuisas, quando em estudos abertos, ou de resultados que sejam do conhecimento dos pesquisadores;

6. Nảo existiráo despesas pesscais para o Sr.(a) em qualquer fase do estudo, incluindo exames e consultas Tambem nao ha compensaçao financeira relacionada à sua participaçăo. Se existir qualquer despesa adicional, ela será absorvida pelo orçamento da pesquisa.

7. Compromisso do pesquisador de utilizar os dados e o material coletado somente para esta pesquisa. 
Em caso de intercorrências clinicas e reaçôes adversas relacionadas ao estudo atual, entrar em contato com:

Prof. Dr. David de Souza Gomez / Dr Edvaldo Vieira UTI Queimados

CIRURGIA PLASTICA - HCFMUSP - Fone (11) 3069-6470

Cristina Sanches Giraud - Telefone (11) 3091-2189 ou (11) 7684-9233

Sivia Regina Cavani Jorge Santos Telefone (11) 3091-2189 ou (11) 7379-2804

Se voco tiver alguma concideraçao ou dúvida sobre a ética da pesquisa, entro em contato com o Comite de Ética em Pesquisa (CEP) - Rua Ovidio Pires de Campos, $225-5^{\circ}$ andar - tel. 3069-6442 rama is 16, 17, 18 ou 20, FAX: 3069-6442 ramal 26 - E-mail: cappesq@hcnet. usp. br

Acredito ter sido suficientemente informado a respeito das informaçōes que li ou que foram lidas para mim descrevendo o estudo" Monitoramento Plasmático de Antimicrobianos em Pacientes Queimados." Eu discuti com o Dr. David de Souza Gomez. sobre a minha decisâo em participar nesse estudo e/ou em consentir que a pessca sob minha tutela partieipe do estudo. Ficaram claros para mim quais săo os propósitos do estudo os procedimentos a serem realizados, seus desconfortos e riscos as garantias de confidencialidade e de esclarecimentos permanentes. Ficou claro também que minha participaçâo é isenta de despesas e que tenho garantie do acesso a tratamento hospitalar quando necessário. Concordo voluntariamente em participar deste estudo e podere retirar o meu consentimento a qualquer momento, antes ou durante o mesmo. scm penalidedes ou prejuizo ou perda de qualquer beneficio que eu possa ter adquirido, ou no meu atendimento neste Serviço.

Assinatura do paciente/representante legal

Data

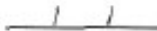

Accinatura de tectomunha

Data

para casos de pacientes menores de 18 anos, analfabetos, semi-analfabetos ou portadores de deficiencia auditiva ou visual.

(Somente para o responsavel do projeto)

Declaro que obtive do forma apropriada e voluntária o Consentimento Livre e Esclarecido deste paciente ou roprocontanto legal para a participaçăo neste estudo 